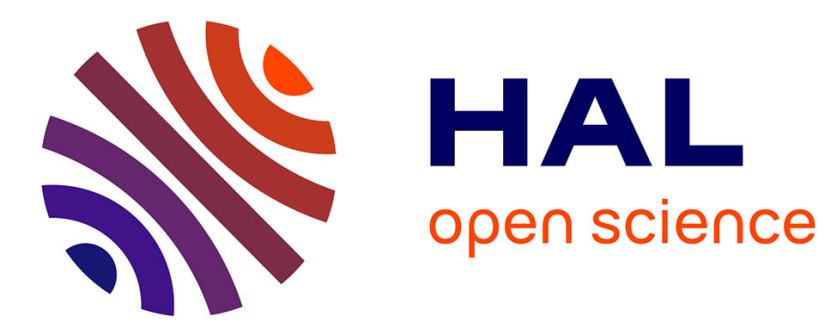

\title{
Molecular Aggregation Structure and Surface Properties of Biomimetic Catechol-Bearing Poly[2-(perfluorooctyl)ethyl acrylate] and Its Application to Superamphiphobic Coatings
}

Wei Ma, Bruno Ameduri, Atsushi Takahara

\section{To cite this version:}

Wei Ma, Bruno Ameduri, Atsushi Takahara. Molecular Aggregation Structure and Surface Properties of Biomimetic Catechol-Bearing Poly[2-(perfluorooctyl)ethyl acrylate] and Its Application to Superamphiphobic Coatings. ACS Omega, 2020, 5 (14), pp.8169-8180. 10.1021/acsomega.0c00439 . hal-02547210

\author{
HAL Id: hal-02547210 \\ https://hal.science/hal-02547210
}

Submitted on 25 May 2021

HAL is a multi-disciplinary open access archive for the deposit and dissemination of scientific research documents, whether they are published or not. The documents may come from teaching and research institutions in France or abroad, or from public or private research centers.
L'archive ouverte pluridisciplinaire HAL, est destinée au dépôt et à la diffusion de documents scientifiques de niveau recherche, publiés ou non, émanant des établissements d'enseignement et de recherche français ou étrangers, des laboratoires publics ou privés. 


\section{Molecular Aggregation Structure and Surface Properties of Biomimetic Catechol-Bearing Poly[2-(perfluorooctyl)ethyl acrylate] and Its Application to Superamphiphobic Coatings}

Wei Ma, Bruno Ameduri, and Atsushi Takahara*

Cite This: ACS Omega 2020, 5, 8169-8180

Read Online

ACCESS | Lلll Metrics \& More | 国 Article Recommendations | sl Supporting Information

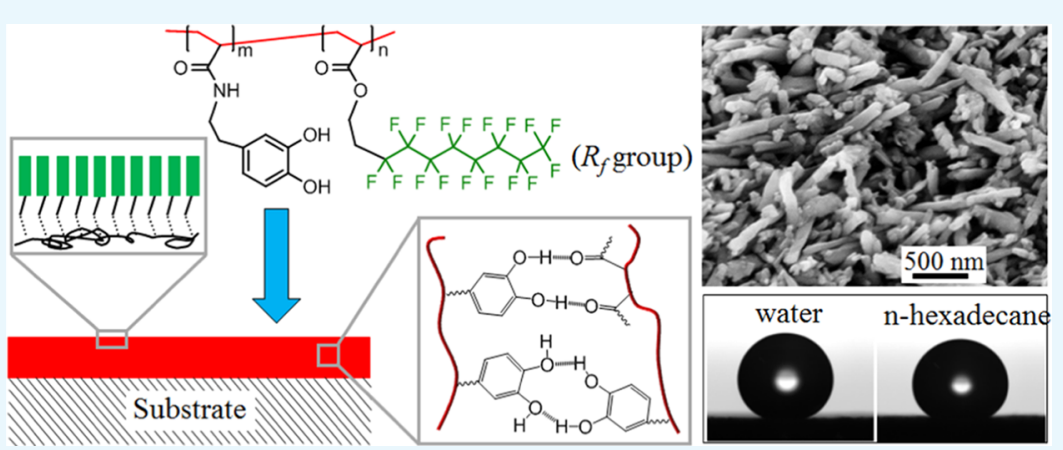

ABSTRACT: The molecular aggregation structure and surface properties of a catechol-bearing fluoropolymer, $\mathrm{P}\left(\mathrm{FAC}_{8}-c o-\right.$ DOPAm), which was synthesized by conventional radical copolymerization of 2-(perfluorooctyl)ethyl acrylate $\left(\mathrm{FAC}_{8}\right)$ and $\mathrm{N}$-(3,4dihydroxyphenethyl)acrylamide (DOPAm), and its application to the superamphiphobic surfaces are presented. The crystallinity of $\mathrm{P}\left(\mathrm{FAC}_{8}-\right.$ co-DOPAm) was lower than that of poly[2-(perfluorooctyl)ethyl acrylate] $\left(\mathrm{PFAC}_{8}\right)$. The perfluoroalkyl $\left(\mathrm{R}_{\mathrm{f}}\right)$ groups were ordered on the surface with $\mathrm{CF}_{3}$ terminals exposed to air, and the $\mathrm{R}_{\mathrm{f}}$ ordering was influenced by thermal history: the thermally annealed film exhibited higher $R_{f}$ ordering than the unannealed one. The surface free energy was estimated to be $\gamma=7.32 \mathrm{~mJ} \mathrm{~m}^{-2}$ for both the unannealed and annealed films. Based on contact angle measurement, various interfacial structures of water and oils in accordance with the surface aggregation structure of $\mathrm{R}_{f}$ groups were proposed. Dewetting of the $\mathrm{PFAC}_{8}$ film at elevated temperature was suppressed by the introduction of catechol groups in the backbone. The degradation temperature of $\mathrm{PFAC}_{8}$ was improved significantly, and the evaporation of the low molar mass-polymer was inhibited by the introduction of catechol groups under both nitrogen and air atmospheres. The hydrophobicity of the copolymer films could be healed after the surface was damaged by vacuum ultraviolet (VUV) irradiation. This copolymer was used to create superamphiphobic fabrics and halloysite nanotube (HNT)-based organic/inorganic hybrid coatings successfully. Wetting behaviors of the superamphiphobic fabrics and coatings both follow the Cassie-Baxter wetting model.

\section{INTRODUCTION}

Due to the high ionization potential and low polarizability of fluorine, fluorinated compounds are known as the most effective materials to provide the ultralow surface free energy required for many applications, such as water and oil repellencies, anticorrosion, antismudge, drag reduction, icereleasing, and fouling resistance. ${ }^{1-7}$ Among the fluorinated materials, fluorinated polymers (or fluoropolymers) have been developed as an important branch since the discovery of poly(tetrafluoroethylene) (PTFE) by Plunkett in 1938. . $^{8,9}$ Fluorinated polymers can be divided into two groups: (I) those where the fluorinated carbons are located in the polymer backbone and (II) those containing fluorinated dangling side groups. In recent years, group (II) has attracted increasing research interest due to the high density of trifluoromethyl $\left(-\mathrm{CF}_{3}\right)$ terminal groups, tunable linkers between the dangling group and the backbone, and the improved solubility and processability compared with that of group (I).$^{10-12}$ In particular, the polymers of perfluoroalkyl-substituted acrylates (PFAs) or methacrylates (PFMAs) maintain both the special surface property of fluoropolymers and the good film-forming characteristic of poly(meth)acrylates. ${ }^{13,14}$

It has been verified that PFAs or PFMAs with more than seven perfluorinated carbon atoms exhibit lower surface free energy than that from PFAs or PFMAs with less than seven

Received: January 31, 2020

Accepted: March 20, 2020

Published: April 1, 2020 

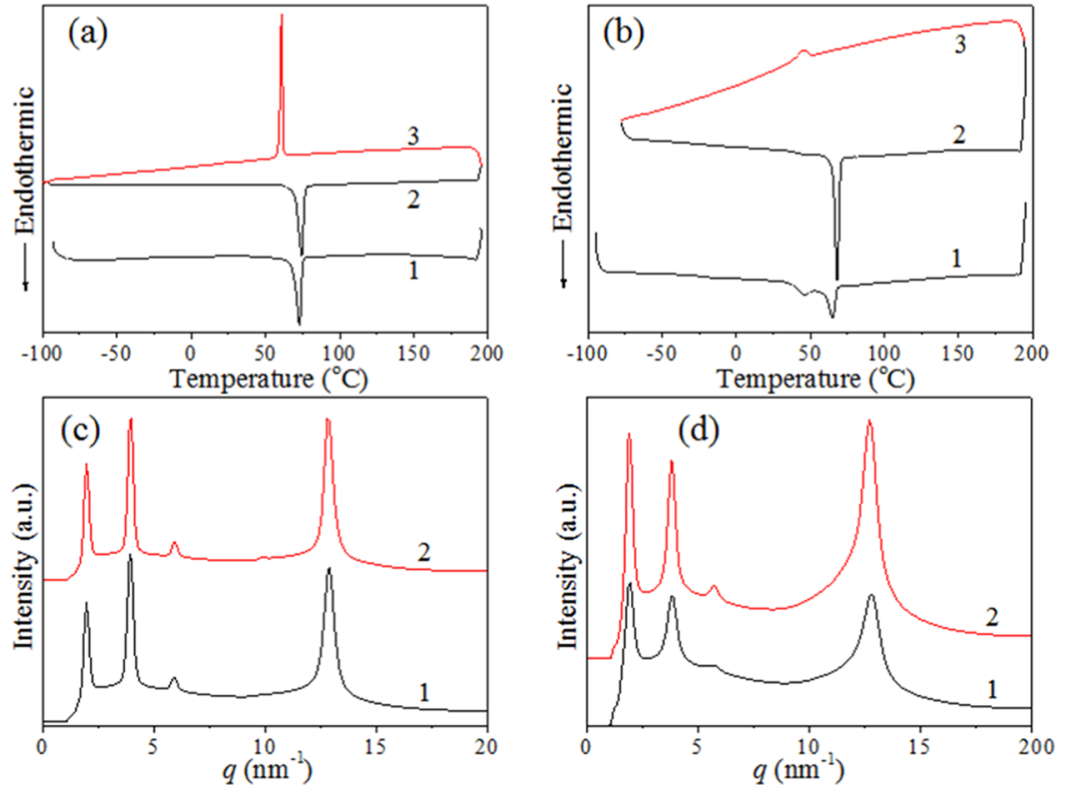

Figure 1. DSC thermograms of (a) $\mathrm{PFAC}_{8}$ and (b) $\mathrm{P}\left(\mathrm{FAC}_{8}\right.$-co-DOPAm) during the first heating $(1,2)$ and cooling (3) process (curve 1 is the sample without any thermal annealing, and curve 2 is the sample after thermal annealing). The wide-angle X-ray diffraction (WAXD) profiles of (c) $\mathrm{PFAC}_{8}$ and (d) $\mathrm{P}\left(\mathrm{FAC}_{8}\right.$-co-DOPAm) (profile 1 is the sample without any thermal annealing, and profile 2 is the sample after thermal annealing).

perfluorinated carbon atoms. ${ }^{15}$ This is because the long-chain perfluoroalkyl groups can be hexagonally packed and form a lamellar phase at the surface region. ${ }^{15,16}$ Although the chemicals containing $\mathrm{C}_{7} \mathrm{~F}_{15}$ or $\mathrm{C}_{8} \mathrm{~F}_{17}$ groups are criticized for the hazardous environmental and health risks, those chemicals are still permitted to be used in some special areas. For example, in the Stockholm Convention, which aims to eliminate or restrict the production and use of persistent organic pollutants, it is shown that the applications of these materials in protective clothing for medical personnel and workers in the oil and gas industry are still allowed because these people require protection from both aqueous and oily fluids. ${ }^{17}$

A major problem that affects the application of PFAs or PFMAs is the weak interfacial adhesion with solid substrates, which is generally associated with poor film stability and durability. To address this issue, several research groups have prepared polymer brushes or introduced adhesive or crosslinkable functional groups into the polymer chains. For example, Yamaguchi et al. grafted poly[2-(perfluorooctyl)ethyl acrylate] $\left(\mathrm{PFAC}_{8}\right)$ brushes from silicon wafer and studied the influence of polydispersity on the molecular aggregation structure and wetting behavior. ${ }^{18}$ Wang and Zuilhof prepared poly[2-(perfluorooctyl)ethyl methacrylate] (PFMAC 8 ) brushes from both smooth and nanostructured substrates and found that the brush films exhibited self-healing properties. $^{19,20}$ Zou et al. introduced glycidyl groups into the hydrophilic sequence of a diblock copolymer containing a $\mathrm{PFAC}_{8}$ segment. The glycidyl groups formed cross-linking points to ensure a stable superamphiphobic coating on fabrics. ${ }^{21}$ Liu's group synthesized poly[3-(triisopropyloxysilyl)propyl methacrylate]-block-poly[2-(perfluorooctyl)ethyl methacrylate] (PIPSMA-b-PFOEMA) block copolymers and used them to fabricate durable self-cleaning coatings. ${ }^{22-25}$ Inspired by the underwater adhesion of mussel foot proteins, Zhou's team reported a random copolymer of a catechol-bearing poly $(1 H, 1 H$-perfluorooctyl methacrylate $)$ and found that the catechol groups could anchor this copolymer onto the surfaces of a variety of solid materials. ${ }^{26}$

However, so far, the molecular aggregation structure of the adhesive groups containing poly(perfluoroalkyl-substituted acrylates) with long-chain perfluoroalkyl groups is still unclear, and the surface properties of these polymers have been rarely studied. Although the first catechol-bearing fluoropolymer was reported by Zhou et al. in 2010 and was used to provide low surface energy surfaces on different materials through selfassembly, ${ }^{26}$ research on this topic is worth continuing to bring more insights. In this article, several new features of catecholbearing $\mathrm{PFAC}_{8}$ are reported: (i) the molecular aggregation structure at the bulk and the surface, (ii) surface wettability, (iii) thermal stability, (iv) healing property of the spin-coated films, and (v) the application of this copolymer to the superamphiphobic fabrics and organic/inorganic hybrid coatings.

\section{RESULTS AND DISCUSSION}

2.1. Molecular Aggregation Structure. Figure $1 \mathrm{a}, \mathrm{b}$ displays the differential scanning calorimetry (DSC) thermograms of $\mathrm{PFAC}_{8}$ and $\mathrm{P}\left(\mathrm{FAC}_{8}-\mathrm{co}\right.$-DOPAm $)$ in the first heating and cooling cycles. An endothermic peak in the heating process, attributed to the melting of the crystalline phase, was observed for both samples. The melting enthalpies of the unannealed $\mathrm{PFAC}_{8}$ and $\mathrm{P}\left(\mathrm{FAC}_{8}\right.$-co-DOPAm $)$ were 19.2 and $3.3 \mathrm{~J} \mathrm{~g}^{-1}$, respectively, while for the annealed samples, the values changed to 20.4 and $9.7 \mathrm{~J} \mathrm{~g}^{-1}$, respectively. The melting enthalpy of $\mathrm{P}\left(\mathrm{FAC}_{8}\right.$-co-DOPAm $)$ was lower than that of $\mathrm{PFAC}_{8}$, indicating that the crystallinity of $\mathrm{PFAC}_{8}$ decreased after the introduction of the catechol group. In the cooling process, the samples displayed an exothermic peak due to the recrystallization. The exothermic enthalpies of $\mathrm{PFAC}_{8}$ and $\mathrm{P}\left(\mathrm{FAC}_{8}\right.$-co-DOPAm $)$ were 19.1 and $2.6 \mathrm{~J} \mathrm{~g}^{-1}$, respectively. The exothermic enthalpy of $\mathrm{PFAC}_{8}$ decreased slightly compared with the endothermic enthalpy of the annealed $\mathrm{PFAC}_{8}$ (decreased by $6.4 \%$ ), implying that the crystallization of $\mathrm{PFAC}_{8}$ was rapid. However, the exothermic enthalpy of 

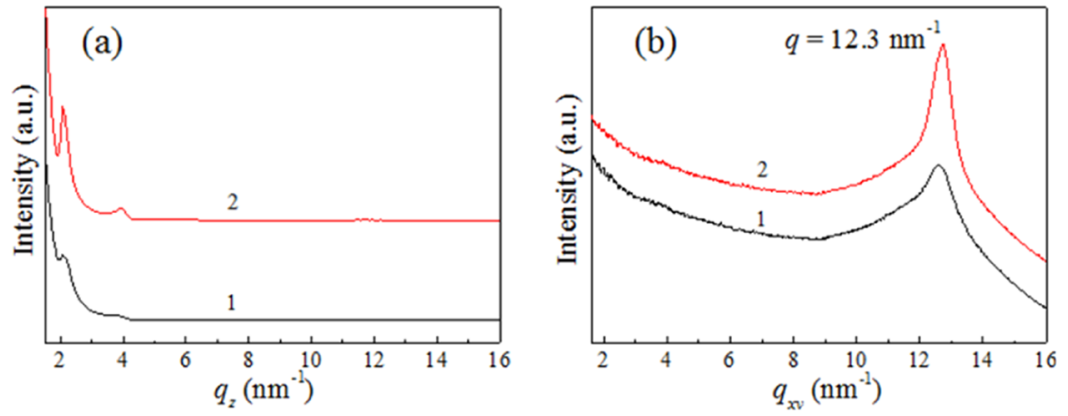

Figure 2. (a) Out-of-plane and (b) in-plane GI-WAXD patterns of the $\mathrm{P}\left(\mathrm{FAC}_{8}\right.$-co-DOPAm) spin-coated film before (1) and after (2) thermal annealing.

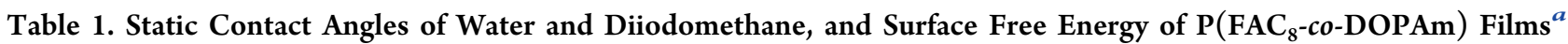

\begin{tabular}{|c|c|c|c|c|c|}
\hline \multirow[b]{2}{*}{ sample } & \multicolumn{2}{|c|}{ static contact angle (deg) } & \multicolumn{3}{|c|}{ surface free energy $\left(\mathrm{mJ} \mathrm{m}^{-2}\right)$} \\
\hline & water & $\mathrm{CH}_{2} \mathrm{I}_{2}$ & $\gamma_{s v}{ }^{d}$ & $\gamma_{s v}{ }^{p}$ & $\gamma$ \\
\hline $\mathrm{P}\left(\mathrm{FAC}_{8}-c o-\mathrm{DOPAm}\right)$ & $123.2 \pm 1.5$ & $104.0 \pm 0.8$ & 6.97 & 0.35 & 7.32 \\
\hline $\mathrm{P}\left(\mathrm{FAC}_{8}-c o-\mathrm{DOPAm}\right)^{b}$ & $123.3 \pm 1.0$ & $104.0 \pm 0.9$ & 6.97 & 0.35 & 7.32 \\
\hline
\end{tabular}

${ }^{a} \gamma_{\mathrm{sv}}{ }^{\mathrm{d}}$, dispersion force component; $\gamma_{\mathrm{sv}}^{\mathrm{p}}$, polar component; $\gamma$, surface free energy. ${ }^{b}$ Annealed at $55^{\circ} \mathrm{C}$ for $12 \mathrm{~h}$.

$\mathrm{P}\left(\mathrm{FAC}_{8}\right.$-co-DOPAm $)$ decreased dramatically compared with the endothermic enthalpy of the annealed $\mathrm{P}\left(\mathrm{FAC}_{8}-\mathrm{co}\right.$ DOPAm) (decreased by $73.2 \%$ ), indicating that the crystallization rate of $\mathrm{P}\left(\mathrm{FAC}_{8}\right.$-co-DOPAm $)$ was slower than that of $\mathrm{PFAC}_{8}$.

Figure 1c,d shows the WAXD profiles of $\mathrm{PFAC}_{8}$ and $\mathrm{P}\left(\mathrm{FAC}_{8}\right.$-co-DOPAm $)$ copolymers. All of the samples exhibited diffraction peaks at $q=1-7$ and $12.3 \mathrm{~nm}^{-1}$. The peaks at a $q$ range of $1-7 \mathrm{~nm}^{-1}$ are consistent with the $0 k 0$ diffraction, implying the existence of a periodic lamellar structure. The $d$ spacing calculated according to the first $0 k 0$ diffraction peak ( $q$ $=1.9 \mathrm{~nm}^{-1}$ ) was $3.3 \mathrm{~nm}$, which is in good agreement with the length of two $\mathrm{R}_{\mathrm{f}}$ groups. ${ }^{27}$ The $d$-spacing calculated according to the diffraction at $q=12.3 \mathrm{~nm}^{-1}$ was $0.51 \mathrm{~nm}$, and it has been ascribed to the distorted hexagonal packing of the $R_{f}$ chains. ${ }^{16}$ The full width at half-maximum (FWHM) of the diffraction peak at $q=12.3 \mathrm{~nm}^{-1}$ was measured to evaluate the packing regularity of the $\mathrm{R}_{\mathrm{f}}$ groups. Prior to thermal annealing, the FWHMs of $\mathrm{PFAC}_{8}$ and $\mathrm{P}\left(\mathrm{FAC}_{8}\right.$-co-DOPAm $)$ were 0.55 and $1.09 \mathrm{~nm}^{-1}$, respectively, while after thermal annealing, they decreased to 0.50 and $0.91 \mathrm{~nm}^{-1}$, respectively. Therefore, although the crystalline structure of $\mathrm{P}\left(\mathrm{FAC}_{8}\right.$-co-DOPAm $)$ was similar to that of $\mathrm{PFAC}_{8}$, the regularity of the $\mathrm{R}_{\mathrm{f}}$ packing structure of $\mathrm{P}\left(\mathrm{FAC}_{8}-\mathrm{co}-\mathrm{DOPAm}\right)$ was poorer than that of $\mathrm{PFAC}_{8}$. After thermal annealing, the FWHM of $\mathrm{P}\left(\mathrm{FAC}_{8}-\mathrm{co}\right.$ DOPAm) and $\mathrm{PFAC}_{8}$ decreased, indicating that the $\mathrm{R}_{\mathrm{f}}$ packing regularity of both these polymers increased.

It can be assumed that the smaller crystallinity, worse $R_{f}$ ordering, and lower crystallization rate of the $\mathrm{P}\left(\mathrm{FAC}_{8}-\mathrm{co}\right.$ DOPAm) copolymer than those of $\mathrm{PFAC}_{8}$ were caused by the existence of hydrogen bonds. Actually, Waite et al. reported that catechol groups were able to form hydrogen bonds with each other. ${ }^{28}$ Here, we studied the molecular interactions of $\mathrm{P}\left(\mathrm{FAC}_{8}\right.$-co-DOPAm) by Fourier transform infrared (FTIR). These results indicate that the catechol groups also formed hydrogen bonds with the carbonyl groups, as the IR spectra of the ester $\mathrm{C}=\mathrm{O}$ stretching of the $\mathrm{P}\left(\mathrm{FAC}_{8}-\mathrm{co}\right.$-DOPAm $)$ copolymer exhibited a shoulder at $1732 \mathrm{~cm}^{-1}$ beside the main peak centered at $1738 \mathrm{~cm}^{-1}$ (Figure S1a, Supporting Information). For many materials, hydrogen bonds are important for the construction of crystalline structures, such as cellulose and poly(vinyl alcohol). ${ }^{29,30}$ However, for the $\mathrm{P}\left(\mathrm{FAC}_{8}\right.$-co-DOPAm $)$ copolymer, the crystal structure is derived from the packing of the $\mathrm{R}_{\mathrm{f}}$ groups, and the interaction among $\mathrm{R}_{\mathrm{f}}$ groups in the crystalline state is weak. ${ }^{10}$ The hydrogen bonds are unfavorable for the $R_{f}$ packing. After thermal annealing, the crystallinity and $\mathrm{R}_{\mathrm{f}}$ ordering increased because the mobility of the polymer chains was improved.

The aggregation structure of the $\mathrm{R}_{\mathrm{f}}$ groups on the surface region was characterized by grazing incidence (GI)-WAXD and X-ray photoelectron spectroscopy (XPS). Figure 2a,b displays the out-of-plane and in-plane GI-WAXD profiles of $\mathrm{P}\left(\mathrm{FAC}_{8}\right.$-co-DOPAm $)$, respectively. In the out-of-plane diffraction profile, peaks at $q=1-6 \mathrm{~nm}^{-1}$, assigned to the lamellar structures, were observed. The in-plane diffraction profile displays the peak at $q=12.3 \mathrm{~nm}^{-1}$, attributed to the hexagonal packing of the $\mathrm{R}_{\mathrm{f}}$ groups. The diffractions at $q=1-6$ and $12.3 \mathrm{~nm}^{-1}$ appeared only in the out-of-plane and in-plane profiles, respectively, suggesting that the lamellar phase was parallel to the film surface and $R_{f}$ groups were orientated perpendicularly to the surface. Moreover, after thermal annealing, the diffraction peak of the packing structure (at $q$ $=12.3 \mathrm{~nm}^{-1}$ ) became sharper $\left(\right.$ FWHM $=0.92 \mathrm{~nm}^{-1}$ ) and more intense compared with that before thermal annealing $\left(\mathrm{FWHM}=1.47 \mathrm{~nm}^{-1}\right)$, indicating that thermal annealing leads to a better surface ordering of the $\mathrm{R}_{f}$ groups. The XPS analysis of the $\mathrm{P}\left(\mathrm{FAC}_{8}-\mathrm{co}\right.$-DOPAm $)$ film implied that the $\mathrm{CF}_{3}$ terminal groups were exposed to the outermost surface of the film, since the $\mathrm{CF}_{3} / \mathrm{CF}_{2}$ atomic ratio ( 0.32 and 0.36 for the unannealed and annealed films, respectively) was higher than the theoretical value of $1 / 7=0.14$ (Figure S2, Supporting Information). These results indicated that the $\mathrm{R}_{\mathrm{f}}$ orientation direction of $\mathrm{P}\left(\mathrm{FAC}_{8}-\mathrm{co}\right.$-DOPAm $)$ on the air/polymer interface is similar to that of $\mathrm{PFAC}_{8}$, as recently reported using heterodyne-detected vibrational sum-frequency generation (HD-VSFG) spectroscopy. ${ }^{31}$

2.2. Surface Wettability of $P\left(F A C_{8}-\right.$ CO-DOPAm) Films. Surface wettability was evaluated by measuring the contact angles. The static contact angles of various polar (water) and nonpolar (diiodomethane, $n$-hexadecane (HD), n-decane, and 
n-octane) liquids were measured and are summarized in Tables 1 and 2. The results showed that the surfaces were not only

Table 2. Static Contact Angles of Various Nonpolar Liquids on $\mathrm{P}\left(\mathrm{FAC}_{8}\right.$-co-DOPAm $)$ Films

\begin{tabular}{cccc} 
& \multicolumn{3}{c}{ static contact angle $(\mathrm{deg})$} \\
\cline { 2 - 4 } sample & $n$-hexadecane & $n$-decane & $n$-octane \\
$\mathrm{P}\left(\mathrm{FAC}_{8}\right.$-co-DOPAm $)$ & $81.4 \pm 0.8$ & $74.8 \pm 0.8$ & $68.2 \pm 0.7$ \\
$\mathrm{P}\left(\mathrm{FAC}_{8} \text {-co-DOPAm }\right)^{a}$ & $81.6 \pm 0.7$ & $75.0 \pm 0.9$ & $68.3 \pm 0.6$ \\
${ }^{a}$ Annealed at $55^{\circ} \mathrm{C}$ for $12 \mathrm{~h}$. & &
\end{tabular}

hydrophobic but also oleophobic. The static contact angles of all of the testing liquids on both of these films are almost identical although the surface orderings of the $R_{f}$ groups on the unannealed and annealed $\mathrm{P}\left(\mathrm{FAC}_{8}-\mathrm{co}-\mathrm{DOPAm}\right)$ films were different. This might be because the film surfaces have sufficient coverage of the $\mathrm{CF}_{2}$ and $\mathrm{CF}_{3}$ groups. Therefore, the difference in the molecular aggregation structure cannot be distinguished by the static contact angles. Some other researchers, such as Hozumi et al., also reported that the static contact angles of polar and nonpolar liquids were not affected by the chemical composition of the sample surfaces if the surface free energies reached their minimum level. ${ }^{32}$ Surface free energies of the $\mathrm{P}\left(\mathrm{FAC}_{8}\right.$-co-DOPAm $)$ films were calculated according to the Owens-Wendt equation ${ }^{33}$ and are listed in Table 1. Both the unannealed and annealed films exhibit the same surface free energy of $\gamma=7.32 \mathrm{~mJ} \mathrm{~m}^{-2}$.

Figures 3 and 4 exhibit the dynamic contact angles of various liquids. The difference between the advancing and receding contact angles was defined as contact angle hysteresis $\left(\theta_{\mathrm{A}}-\right.$ $\left.\theta_{\mathrm{R}}\right)$, and the tilting angle of the substrate, at which the droplet started to slide, was defined as the sliding angle. For water, the advancing angle almost did not change, while the receding angle increased from 90.2 to $103.5^{\circ}$ after thermal annealing. For the nonpolar liquids, the changes in the advancing and receding angles before and after thermal annealing were slight (Figure 3), while the changes in the contact angle hysteresis and sliding angle were notable (Figure 4). It is worth noting that the thermal annealing exerted opposite effects on the contact angle hysteresis and sliding angle for water and oils. After thermal annealing, the contact angle hysteresis and sliding angle of water decreased, while that of the nonpolar oils increased.

According to the wettability and surface aggregation structure, the possible interfacial structures of water and oil on the $\mathrm{P}\left(\mathrm{FAC}_{8}\right.$-co-DOPAm) films were proposed (Scheme 1 ). Before thermal annealing, the $R_{f}$ groups had a poor surface ordering and, therefore, a high mobility. Upon contact with water, those loosely ordered $\mathrm{R}_{\mathrm{f}}$ groups would rearrange to reduce the interfacial energy through the formation of hydrogen bonds between the carbonyl groups and water molecules. Consequently, the contact angle hysteresis and sliding angle of water were high. After thermal annealing, the mobility of $R_{f}$ groups decreased because the packing became more ordered. Consequently, the rearrangement of the $R_{f}$ groups on the annealed film became difficult; therefore, the contact angle hysteresis and sliding angle of water decreased. For nonpolar liquids, they cannot form hydrogen bonds with the carbonyl groups. When those liquids were placed on the surface, the rearrangement of the $\mathrm{R}_{\mathrm{f}}$ groups did not occur. Moreover, before thermal annealing, the surface was "liquidlike" for nonpolar liquids, as the mobility of the $\mathrm{R}_{\mathrm{f}}$ groups was high; however, after thermal annealing, the film became "solidlike" due to the restricted mobility of the $\mathrm{R}_{\mathrm{f}}$ groups. The liquidlike surfaces usually exhibit a lower contact angle hysteresis than the solidlike surfaces because of the formation of a dynamic "liquid-liquid" interface with the testing liquids. Applying the concept of the liquid-liquid interface to prepare low hysteresis surfaces has been discussed in several publications, particularly by McCarthy's and Hozumi's groups. $^{34-39}$

2.3. Thermal Stability of the $P\left(F A C_{8}-C O-D O P A m\right)$

Films. Thermal stability is an important parameter that affects the application of polymer films. One of the major problems that impede film application at high temperatures is dewetting, which usually causes rupture and breakup of the continuous polymer films. Dewetting occurs easily if an unstable or metastable thin film is heated above its glass-transition temperature. ${ }^{40}$ It is influenced by several factors, such as wettability of the substrates, viscoelasticity of the polymer, and the interfacial energy between the polymer and the substrate. Sheiko et al. studied the dewetting of $\mathrm{PFMAC}_{8}$ films on a glass substrate. ${ }^{41}$ They reported that such a dewetting of PFMAC $_{8}$ occurred as a function of the film thickness: (a) thick films melted above the isotropization temperature $\left(90^{\circ} \mathrm{C}\right)$ and the disordered melt formed macroscopic dewetting on the ordered sublayers; (b) the sublayers collapsed via a stepwise coagulation of the bilayers, i.e., a bilayer started to dewet the next bilayer only after the top layer had collapsed into microscopic droplets; and (c) this process was repeated until a thin film with the thickness of only one and a half bilayers remained. In this work, the detailed dewetting mechanism of the $\mathrm{PFAC}_{8}$ film was not studied. We anticipate that it has a similar dewetting behavior to that of the $\mathrm{PFMAC}_{8}$ film since the chemical structure and molecular aggregation state of $\mathrm{PFAC}_{8}$ are close to those of PFAMC 8 . As shown in Figure 5a, upon heating to $90^{\circ} \mathrm{C}$, the continuous film of $\mathrm{PFAC}_{8}$ dewetted
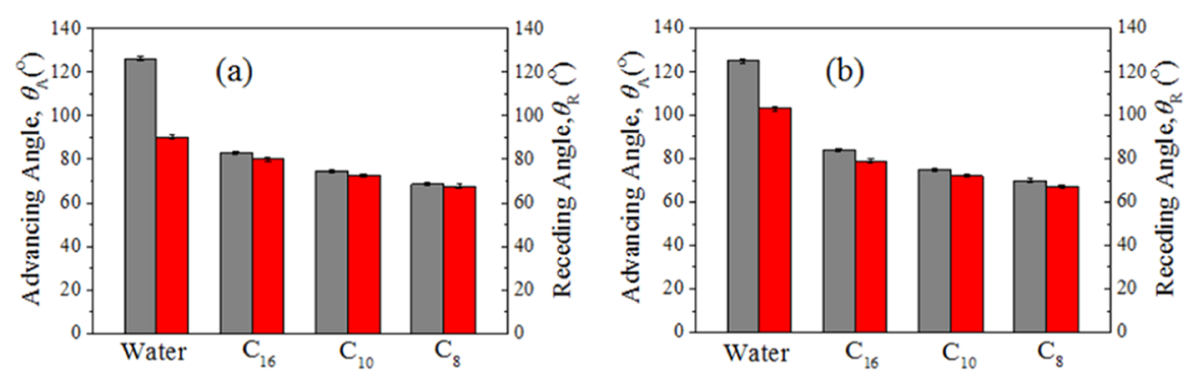

Figure 3. Changes in the advancing and receding angles of $\mathrm{P}\left(\mathrm{FAC}_{8}\right.$-co-DOPAm $)$ for water, $n$-hexadecane $\left(\mathrm{C}_{16}\right), n$-decane $\left(\mathrm{C}_{10}\right)$, and $n$-octane $\left(\mathrm{C}_{8}\right)$ before (a) and after (b) thermal annealing. The gray and red colors indicate the advancing and receding angles, respectively. 

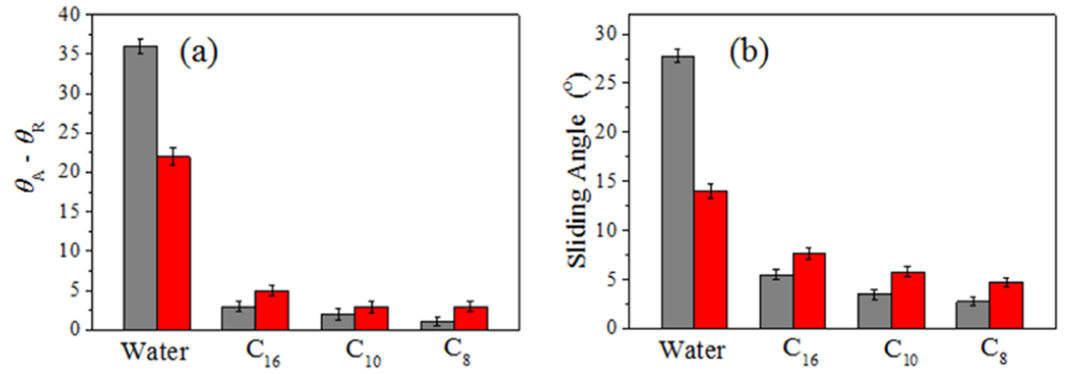

Figure 4. Changes in the contact angle hysteresis (a) and sliding angle $(\mathrm{b})$ of $\mathrm{P}\left(\mathrm{FAC}_{8}\right.$-co-DOPAm $)$ for water, $n$-hexadecane $\left(\mathrm{C}_{16}\right), n$-decane $\left(\mathrm{C}_{10}\right)$, and $n$-octane $\left(\mathrm{C}_{8}\right)$ before (gray columns) and after (red columns) thermal annealing.

Scheme 1. Schematic Presentation of Water and Oil Interfacial Structures on the $\mathrm{P}\left(\mathrm{FAC}_{8}\right.$-co-DOPAm $)$ Film before and after Thermal Annealing ${ }^{a}$ (a)

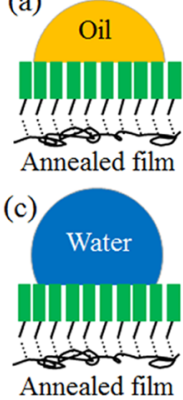

(b)

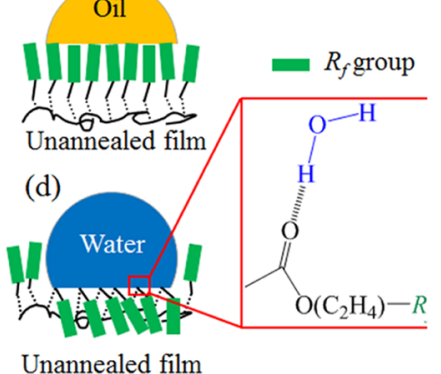

${ }^{a}(\mathrm{a}, \mathrm{c})$ "Liquid-solid" interface. (b) Liquid-liquid interface. (d) Surface rearrangement.

into disconnected microdroplets with an average size of ca. 50 $\mu \mathrm{m}$ within $10 \mathrm{~min}$.

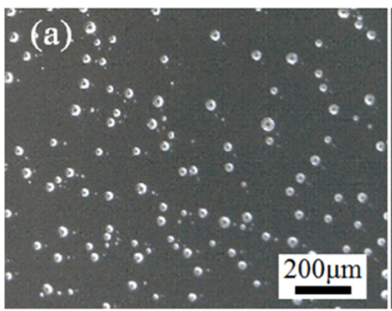

\section{(b)}

Figure 5. Optical microscopic images of the surfaces of the (a) $\mathrm{PFAC}_{8}$ film after heating at $90{ }^{\circ} \mathrm{C}$ for $10 \mathrm{~min}$ and (b) $\mathrm{P}\left(\mathrm{FAC}_{8}-\mathrm{co}\right.$ DOPAm) film after heating at $150{ }^{\circ} \mathrm{C}$ for $30 \mathrm{~min}$. The films were spin-coated on silicon wafers, and the white dots in (a) are the dewetted polymer.

Suppression of dewetting is critically important for improving the thermal stability of polymer films. Several strategies to suppress dewetting have been developed, such as introducing special interactions between polymer chains and the substrate by modification of polymers with functional groups to reduce the mobility of polymer chain segments, ${ }^{42-44}$ cross-linking of polymer films by irradiation or the addition of cross-linking agents, ${ }^{40}$ adding nanofillers to increase the interfacial roughness or to increase the viscosity of the polymer film by the polymer-filler interaction, ${ }^{45}$ and using capping materials such as graphene and $\mathrm{MoS}_{2}$ to suppress the surface fluctuation, thus inhibiting dewetting. ${ }^{46}$ To avoid the dewetting of the $\mathrm{PFAC}_{8}$ film during the imprinting of nanostructures, Honda et al. proposed a room-temperature imprinting method. ${ }^{10}$ However, the use of the imprinted $\mathrm{PFAC}_{8}$ film at elevated temperatures is still a challenge. The current study verified that the catechol groups of $\mathrm{P}\left(\mathrm{FAC}_{8}-\mathrm{co}\right.$ DOPAm) can form hydrogen bonds with the carbonyl groups; consequently, the mobility of the polymer chain was restricted. Moreover, as a bioinspired adhesive group, the catechol units have versatile adhesion ability with various solid substrates. ${ }^{47-53}$ These two features imply that the thermal stability of the $\mathrm{P}\left(\mathrm{FAC}_{8}\right.$-co-DOPAm $)$ film should be higher compared to that of the $\mathrm{PFAC}_{8}$ film. As shown in Figure 5b, after being heated to $150{ }^{\circ} \mathrm{C}$ for $30 \mathrm{~min}$, the film was kept intact, and the dewetting phenomenon did not occur. This result indicates that the dewetting of $\mathrm{PFAC}_{8}$ was completely inhibited by the introduction of catechol groups in the backbone.

In addition to the dewetting resistance, the thermal decomposition temperature of $\mathrm{PFAC}_{8}$ was also improved by the introduction of catechol groups. Figure 6 displays the thermogravimetric analysis (TGA) thermograms of $\mathrm{P}\left(\mathrm{FAC}_{8^{-}}\right.$ co-DOPAm) and $\mathrm{PFAC}_{8}$ under nitrogen and air atmospheres, in which (a) and (b) show the overall weight loss and (c) and (d) show the weight loss region from 0 to $20 \%$. According to these thermograms, $\mathrm{PFAC}_{8}$ exhibited a slight weight loss from $62{ }^{\circ} \mathrm{C}$ under nitrogen and $65{ }^{\circ} \mathrm{C}$ in air, and the amounts were both about $1 \%$. The major weight loss of $\mathrm{PFAC}_{8}$ started from $205{ }^{\circ} \mathrm{C}$ under nitrogen and $160{ }^{\circ} \mathrm{C}$ in air. On the contrary, the weight loss of $\mathrm{P}\left(\mathrm{FAC}_{8}\right.$-co-DOPAm $)$ occurred in one step only, which started from $255{ }^{\circ} \mathrm{C}$ under nitrogen and $235{ }^{\circ} \mathrm{C}$ in air. Therefore, the thermal decomposition temperature of $\mathrm{P}\left(\mathrm{FAC}_{8}-\right.$ co-DOPAm) was significantly higher than that of $\mathrm{PFAC}_{8}$ under both of the nitrogen and air atmospheres. The slight weight loss of $\mathrm{PFAC}_{8}$ in the low-temperature region was likely due to the evaporation of the low molar mass polymer but not the solvent residue because, before TGA measurements, the samples were dried sufficiently (under $50{ }^{\circ} \mathrm{C}$ in vacuum for $48 \mathrm{~h}$ ). This result indicates that the existence of catechol groups in the polymer chain improved the thermal stability of $\mathrm{PFAC}_{8}$ and also inhibited the evaporation of low molar mass polymer. It is believed that the existence of multiple hydrogen bonds contributed to the improved thermal stability, which is favorable for preventing or reducing the entry of $\mathrm{C}_{8} \mathrm{~F}_{17}$ chemicals into the environment at elevated temperatures.

2.4. Healing Property of the $P\left(F A C_{8}-C_{-}-D O P A m\right)$ Films. As reported in previous works, the hydrophobic character of the fluoropolymer brush can self-heal after incurring damages by plasma or UV irradiation. ${ }^{19,20}$ This is because the $\mathrm{R}_{\mathrm{f}}$ group has a strong tendency to rearrange toward the outermost surface when the damaged polymer brush is heated to a temperature above the glass-transition temperature. The driving force for the self-healing is the low surface energy of the fluorinated materials. However, to date, 

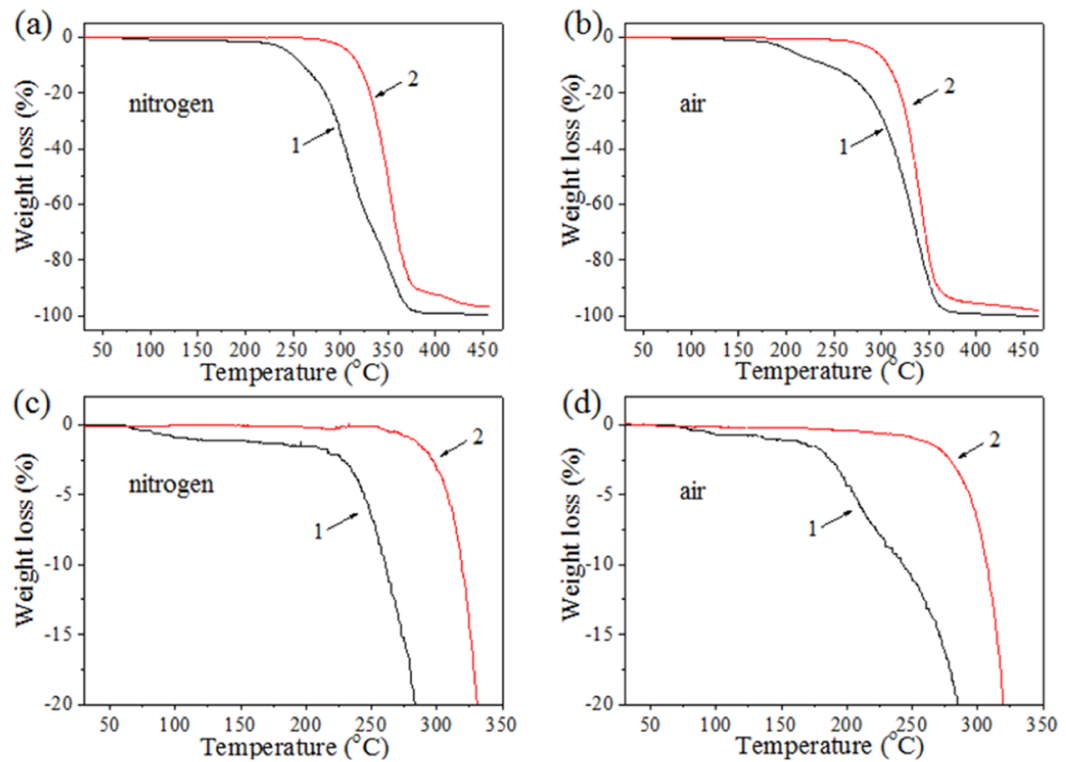

Figure 6. TGA thermograms of $\mathrm{PFAC}_{8}(1)$ and $\mathrm{P}\left(\mathrm{FAC}_{8}-\mathrm{co}\right.$-DOPAm $)(2)$ under nitrogen $(\mathrm{a}, \mathrm{c})$ and air $(\mathrm{b}, \mathrm{d})$ atmospheres, heated at $2{ }^{\circ} \mathrm{C}$ min ${ }^{-1}$.
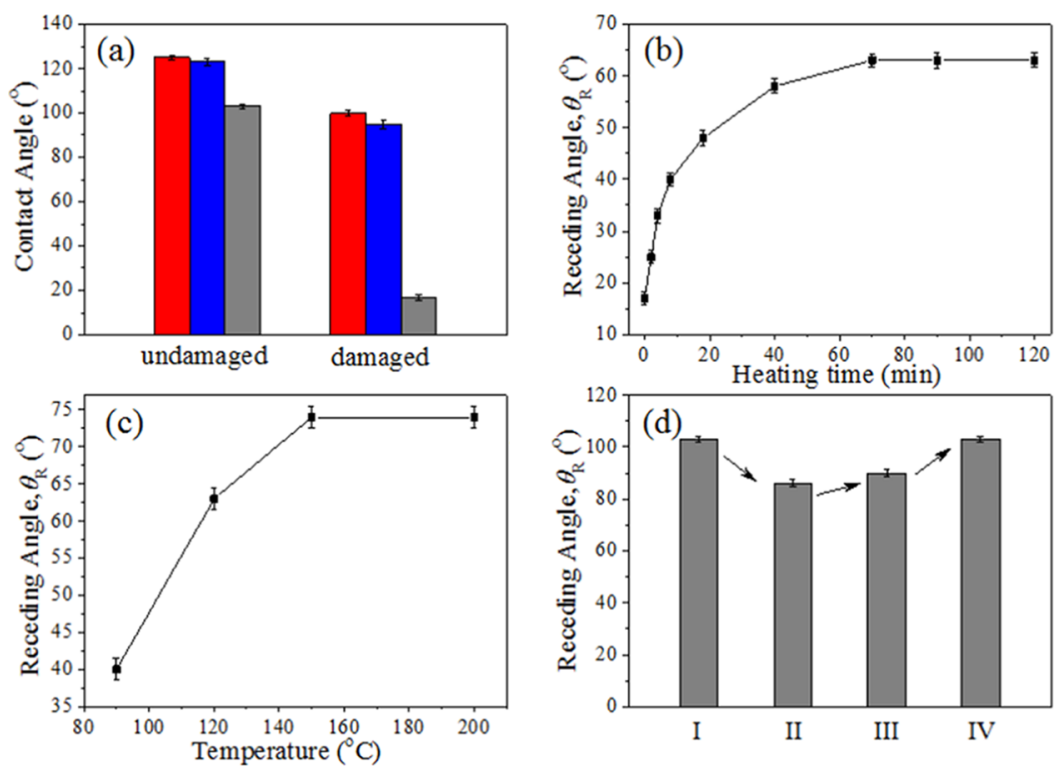

Figure 7. (a) Advancing (red column), static (blue column), and receding (gray column) water contact angles of the $\mathrm{P}\left(\mathrm{FAC}_{8}\right.$-co-DOPAm) film before (undamaged) and after (damaged) VUV irradiation for $2 \mathrm{~min}$. (b) Evolution of the water receding angle on the damaged (by VUV irradiation for $2 \mathrm{~min}) \mathrm{P}\left(\mathrm{FAC}_{8}-\mathrm{co}\right.$-DOPAm) film over heating under $120^{\circ} \mathrm{C}$. (c) Water receding angle of the damaged (by VUV irradiation for 2 min) $\mathrm{P}\left(\mathrm{FAC}_{8}\right.$-co-DOPAm) film after being heated at different temperatures for $2 \mathrm{~h}$. (d) Water receding angle of the slightly damaged (by VUV irradiation for $20 \mathrm{~s}) \mathrm{P}\left(\mathrm{FAC}_{8}\right.$-co-DOPAm) film at different stages (I, before damage; II, damaged by irradiation; III, heated at $120^{\circ} \mathrm{C}$ for $2 \mathrm{~h}$ after damage; IV, further annealed at $55{ }^{\circ} \mathrm{C}$ for $12 \mathrm{~h}$ ).

healing of the spin-coated fluoropolymer films has been rarely studied because these fluoropolymer films are usually unstable and would dewet the substrates during heat treatment. Recently, healable fluorinated polymeric materials based on Diels-Alder chemistry were reported by several groups. ${ }^{54,55}$ However, in those studies, healing behavior of the surface hydrophobicity was not mentioned.

In this study, the healing properties of the $\mathrm{P}\left(\mathrm{FAC}_{8}-\mathrm{co}\right.$ DOPAm) film were studied. Figure $7 \mathrm{a}$ shows the static, advancing, and receding water contact angles of the polymer film before and after vacuum ultraviolet (VUV) irradiation for $2 \mathrm{~min}$. Prior to irradiation, the static, advancing, and receding contact angles were $125.5,123.3$, and $103.5^{\circ}$, respectively.
After VUV irradiation for $2 \mathrm{~min}$, those angles decreased to $100.2,95.4$, and $17.8^{\circ}$, respectively. The decrease in contact angles indicated that the surface became hydrophilic. This is because under VUV irradiation, the ester linkage of the side chains decomposed into carboxylic acid groups, causing the loss of $\mathrm{R}_{\mathrm{f}}{ }^{19}$ Compared with the static and advancing angles, the receding angle was more sensitive to surface damage, as it reduced more significantly after VUV irradiation. Therefore, the receding angle was applied to evaluate the healing efficiency.

Figure $7 \mathrm{~b}$ exhibits the evolution of the water receding angle of the damaged $\mathrm{P}\left(\mathrm{FAC}_{8}-\mathrm{co}-\mathrm{DOPAm}\right)$ film under heating at $120{ }^{\circ} \mathrm{C}$. With the extension of the heating time, the receding 
angle gradually increased and reached the maximum value of $63.0^{\circ}$ after $70 \mathrm{~min}$. This indicates that the $\mathrm{R}_{\mathrm{f}}$ groups gradually migrated to the surface to increase the hydrophobicity. However, the receding angle did not recover to the original value. It can be assumed that this arises from the low mobility of the polymer chains due to the existence of hydrogen bonds. Consequently, only the $\mathrm{R}_{\mathrm{f}}$ groups on the top layer can migrate to the outermost surface, which is insufficient to cover the damaged area completely. It can be expected that, as the temperature increased, the hydrogen bonds would become more dynamic and, therefore, allow more $\mathrm{R}_{\mathrm{f}}$ groups to migrate to the surface. Figure $7 \mathrm{c}$ shows the receding angles of the repaired films that were repaired by heating at various temperatures for $2 \mathrm{~h}$. As the heating temperature increased from 90 to $150{ }^{\circ} \mathrm{C}$, the receding contact angle increased from 40.1 to $74.0^{\circ}$. However, when the temperature further increased, the receding angle did not further increase. This might be due to the cross-linking of the catechol groups due to the oxidation at relatively high temperatures.

Conversely, the repairing efficiency was also affected by the degree of damage (Figure $7 \mathrm{~d}$ ). When the film was damaged slightly by VUV irradiation for $20 \mathrm{~s}$, the water receding angle decreased to $85.9^{\circ}$. The water receding angle increased to $90.0^{\circ}$ after heating at $120^{\circ} \mathrm{C}$ for $2 \mathrm{~h}$. Upon further annealing at $55{ }^{\circ} \mathrm{C}$ for $12 \mathrm{~h}$, the water receding angle further increased to $103.2^{\circ}$. However, the receding angle of the heavily damaged film did not further increase after further annealing under the same conditions. This suggests that the $\mathrm{R}_{\mathrm{f}}$ groups of the heavily damaged film could no longer recover to the original surface aggregation state, while the slightly damaged film could by heated and annealed.

2.5. $P\left(F A C_{8}-C O-D O P A m\right)$ Copolymer Used for the Fabrication of Superamphiphobic Coatings. Superamphiphobic surfaces, which exhibit water and oil contact angles higher than $150^{\circ}$, have drawn global research interest. However, compared with superhydrophobic surfaces, the fabrication of superamphiphobic surfaces remains a great challenge. Previous studies indicated that superamphiphobic surfaces generally rely on fluorinated surface chemistry and special surface topographies, such as re-entrant surface curvature. $^{56,57}$ To date, various kinds of techniques have been established to create superamphiphobic surfaces. These techniques can be divided into two categories: two-step and single-step approaches. The two-step approach involves the creation of a surface structure and subsequent low-surfaceenergy treatment. ${ }^{58}$ In the single-step approach, the surface structure and low surface energy are generated simultaneously. ${ }^{59}$ Among the two-step approaches, coating the existing fabrics with low surface free energy materials has attracted great research attention and has been regarded as one of the most promising strategies for producing superamphiphobic materials for daily use. ${ }^{21,60-62}$ Among the single-step methods, the organic/inorganic hybrid superamphiphobic coatings are of particular interest due to the abundant coating techniques, low reliance on equipment, wide choice of inorganic nanobuilding blocks, and scalability. $^{22,59,63,64}$

Our study demonstrates that $\mathrm{P}\left(\mathrm{FAC}_{8}\right.$-co-DOPAm $)$ was applicable in the preparation of both superamphiphobic fabrics and organic/inorganic hybrid coatings. For coating fabrics, the coating solution was prepared by dissolving $\mathrm{P}\left(\mathrm{FAC}_{8}-\mathrm{co}\right.$ DOPAm) in HCFC-225s to form a homogeneous solution with a concentration of $1 \mathrm{wt} \%$. The solution can be applied to

fabrics through a dip-coating or spray-coating method. In this study, dip-coating was employed for the coating treatment of fabrics. After coating, the fabric was dried by $\mathrm{N}_{2}$ blowing. Figure $8 \mathrm{a}-\mathrm{d}$ shows the scanning electron microscopic (SEM)

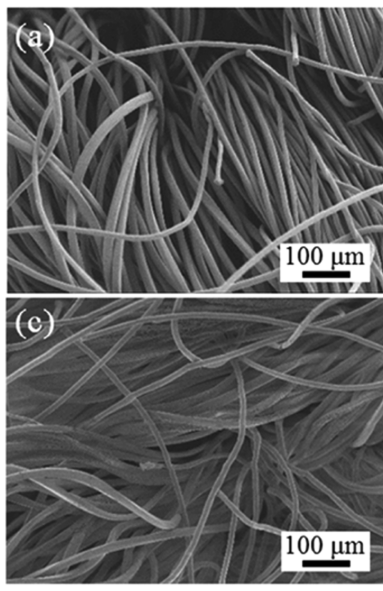

(e)

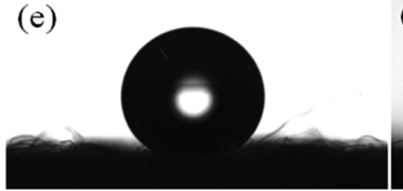

Figure 8. SEM images of (a, b) pristine cotton fabric and (c, d) $\mathrm{P}\left(\mathrm{FAC}_{8}\right.$-co-DOPAm $)$ coated fabric. Images of $(\mathrm{e})$ water and $(\mathrm{f}) n$ hexadecane droplets on the $\mathrm{P}\left(\mathrm{FAC}_{8}\right.$-co-DOPAm $)$ coated fabric.

images of the fabrics before and after coating with the polymer. Prior to coating, the fabric fibers appeared smooth, while after coating, some crater structures were observed on the fibers. This may be due to water condensation during the slow solvent evaporation. Some of the fibers were bonded to each other due to the adhesion property of the catechol groups in $\mathrm{P}\left(\mathrm{FAC}_{8}-\mathrm{co}\right.$-DOPAm $)$. The water and oil repellencies of the coated fabric were evaluated by measuring the contact angles of water and $n$-hexadecane (HD). The contact angles of water and HD were 169.3 and $153.2^{\circ}$, respectively, indicating that the coated fabric was superamphiphobic (Figure 8e,f). The sliding angle of water was $3.5^{\circ}$, while the $\mathrm{HD}$ droplet was pinned on the fabric and could not slide off even when the substrate was placed perpendicularly.

$$
\begin{aligned}
& \cos \theta_{\mathrm{W}}=r \cos \theta_{0} \\
& \cos \theta_{\mathrm{C}-\mathrm{B}}=f-1+f \cos \theta_{0}
\end{aligned}
$$

Wenzel's (eq 2) and Cassie-Baxter's (eq 3) equations are usually applied to describe the contact states of liquids on substrates. In these equations, $\theta_{0}$ is the Young contact angle, which is obtained on the smooth surface with the same surface chemistry; $r$ is the roughness factor; while $f$ denotes the fraction of the solid/liquid contact area. The $\theta_{0}$ values of water and $\mathrm{HD}$ are 123.2 and $81.4^{\circ}$, respectively. According to these values, only the Cassie-Baxter equation is valid. Therefore, this superamphiphobic fabric follows the Cassie-Baxter wetting model. The $f$ values of water and HD were calculated to be 0.038 and 0.093, respectively. According to this result, the pinning of the HD droplet was ascribed to the relatively high solid/liquid contact area. The influence of the thermal annealing on the wettability of the $\mathrm{P}\left(\mathrm{FAC}_{8}-\mathrm{co}\right.$-DOPAm $)$ coated fabric was also studied. However, the results showed 
that thermal annealing almost did not affect the wettability of both water and oils. This indicates that the wettability of the $\mathrm{P}\left(\mathrm{FAC}_{8}\right.$-co-DOPAm $)$ coated fabric was dominated by the morphology rather than the surface aggregation structure of the $\mathrm{R}_{\mathrm{f}}$ groups.

For organic/inorganic hybrid superamphiphobic coatings, halloysite nanotube (HNT), which is a natural tubular clay, ${ }^{65}$ was used as the nanobuilding block. The coating was prepared by dropping and evaporation of a mixed solution of $\mathrm{P}\left(\mathrm{FAC}_{8^{-}}\right.$ co-DOPAm) and HNT onto the substrates. The surface topography and wettability of the obtained coatings were observed and evaluated by SEM and contact angle measurement, respectively. As shown in Figure 9a,c, the coating

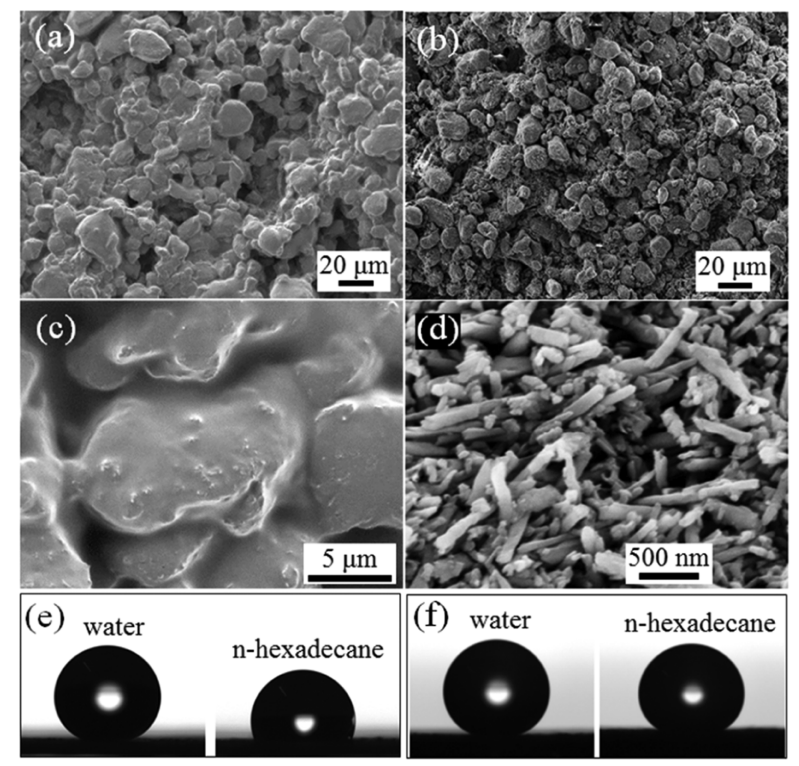

Figure 9. SEM images of the coatings prepared by (a, c) $\mathrm{P}\left(\mathrm{FAC}_{8}-\mathrm{co}\right.$ DOPAm $) / H N T(\mathrm{w} / \mathrm{w}=1: 2)$ mixed solution and $(\mathrm{b}, \mathrm{d}) \mathrm{P}\left(\mathrm{FAC}_{8}-\mathrm{co}-\right.$ DOPAm)-adsorbed HNT solution. Images of water and $n$-hexadecane droplets on the coatings prepared by (e) $\mathrm{P}\left(\mathrm{FAC}_{8}-\mathrm{co}\right.$-DOPAm $) / \mathrm{HNT}$ $(\mathrm{w} / \mathrm{w}=1: 2)$ mixed solution and $(\mathrm{f}) \mathrm{P}\left(\mathrm{FAC}_{8}-c o-\mathrm{DOPAm}\right)$-adsorbed HNT solution.

prepared from the solution with a weight ratio of $\mathrm{P}\left(\mathrm{FAC}_{8}\right.$-coDOPAm $) / H N T=1: 2$ appeared rough at a microscale but flat at a nanoscale. The microscale roughness was formed by the aggregation of HNT. However, the excess of the polymer filled up the gaps between the individual HNTs during solvent evaporation and caused a flat topography at the nanoscale. Contact angle measurement indicated that this coating was superhydrophobic with a water contact angle of $172.5^{\circ}$ despite the lack of nanoscale roughness (Figure 9e). However, it was not superoleophobic, as the contact angle of $\mathrm{HD}$ was $110.3^{\circ}$ only. Bayer et al. reported that superoleophobic and superhydrophobic nanocomposite coatings with micro-/nanohierarchical morphologies can be created by spray-coating waterborne nanoparticle-fluoropolymer suspensions using acetone as a cosolvent or maintaining the substrate at elevated temperatures. ${ }^{66,67}$ In this work, considering that the catecholbearing materials displayed good adhesion with various solid materials, ${ }^{47-51}$ it is believed that HNT, the external surface of which is composed of silica, can be adsorbed by a layer of $\mathrm{P}\left(\mathrm{FAC}_{8}\right.$-co-DOPAm $)$ if the excess polymer is removed before coating preparation, which would allow the exposure of nanoscale roughness.
As shown in Figure 10, after removing the excess polymer through centrifugation and washing with clean HCFC-225s,

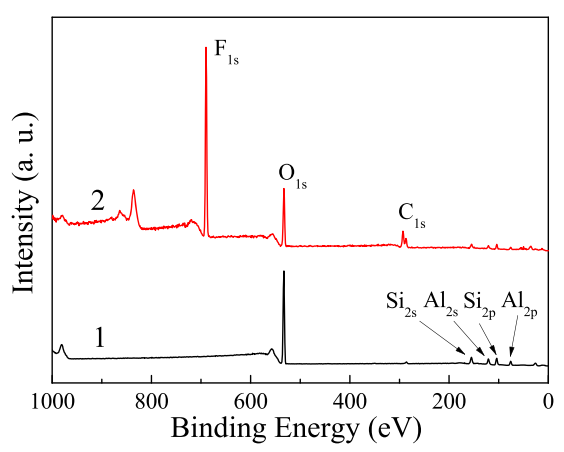

Figure 10. XPS profiles of the pristine (1) and $\mathrm{P}\left(\mathrm{FAC}_{8}-\mathrm{co}\right.$-DOPAm)adsorbed (2) HNT.

the HNT still exhibited an intense $F_{1 s}$ peak in the XPS profile, implying that $\mathrm{HNT}$ was coated by a layer of $\mathrm{P}\left(\mathrm{FAC}_{8}-\mathrm{co}\right.$ DOPAm). As observed by SEM, the coating prepared from the solution of $\mathrm{P}\left(\mathrm{FAC}_{8}\right.$-co-DOPAm $)$-adsorbed $\mathrm{HNT}$ appeared rough at both the micro- and nanoscales (Figure 9b,d). At the microscale, the surface topography was similar to that of the above $\mathrm{P}\left(\mathrm{FAC}_{8}\right.$-co-DOPAm $) / \mathrm{HNT}$ composite coating. At the nanoscale, the HNT agglomerates were clearly observed, and the remaining gaps between the individual HNTs led to a nanoporous morphology. The water and HD contact angles were 172.6 and $160.5^{\circ}$, respectively (Figure 9f). According to Cassie-Baxter's equation, the solid/liquid contact fractions of water and HD were calculated to be 0.018 and 0.050 , respectively. Due to the small solid/liquid contact fractions, both water and HD droplets could slide off the coating, and the water and $\mathrm{HD}$ sliding angles were 2.0 and $15.0^{\circ}$, respectively. This wettability is similar to that of the $\mathrm{P}\left(\mathrm{FAC}_{8}\right.$-co-DOPAm $)$-modified HNT coating, in which an aminosilane was applied to assist in the polymer modification of HNT, as reported previously. ${ }^{64}$ However, for long-term underwater use, the aminosilane-assisted $\mathrm{P}\left(\mathrm{FAC}_{8}\right.$-co-DOPAm $)$ modification of HNT is more favorable because the interactions between catechol group and silica are unstable in water. $^{64}$ The superamphiphobic coating of $\mathrm{P}\left(\mathrm{FAC}_{8}\right.$-coDOPAm)-adsorbed HNT was mechanically durable, as it can resist water scouring and finger touching, although the excess polymer has been removed. It is believed that this is because the free catechol groups on the $\mathrm{P}\left(\mathrm{FAC}_{8}\right.$-co-DOPAm $)$-adsorbed HNT can bind the nanotubes through multiple hydrogen bonds, as shown in Scheme 2. The surface wettability of this superamphiphobic coating was not affected by the thermal treatment, since the $\mathrm{R}_{\mathrm{f}}$ groups of the $\mathrm{P}\left(\mathrm{FAC}_{8}\right.$-co-DOPAm $)$ adsorption layer were in a disordered state regardless of thermal annealing. ${ }^{64}$

\section{CONCLUSIONS}

A catechol-bearing fluoropolymer, $\mathrm{P}\left(\mathrm{FAC}_{8}\right.$-co-DOPAm $)$, was synthesized by the radical copolymerization of $\mathrm{FAC}_{8}$ and DOPAm. The influence of catechol groups on the molecular aggregation structure of $\mathrm{FAC}_{8}$ was studied by DSC, WAXD, GI-WAXD, and XPS. Due to the existence of hydrogen bonds between catechol groups and carbonyl units, the crystallinity and crystallization rate of $\mathrm{P}\left(\mathrm{FAC}_{8}-\mathrm{co}-\mathrm{DOPAm}\right)$ decreased significantly compared with those of $\mathrm{PFAC}_{8}$. The $\mathrm{R}_{\mathrm{f}}$ groups were ordered on the surface with the $\mathrm{CF}_{3}$ terminal groups 
Scheme 2. Proposed Molecular Interaction of the Superamphiphobic Coating Prepared from the $\mathrm{P}\left(\mathrm{FAC}_{8}-\mathrm{co}\right.$ DOPAm)-Adsorbed HNTs

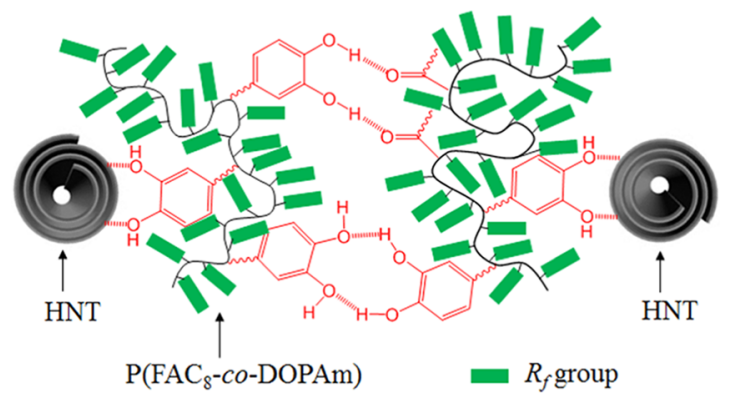

exposed to the outermost surface. The ordering of the $R_{f}$ groups was affected by thermal history: the thermally annealed $\mathrm{P}\left(\mathrm{FAC}_{8}-\mathrm{co}-\mathrm{DOPAm}\right)$ film exhibited better $\mathrm{R}_{\mathrm{f}}$ ordering than the unannealed one. In accordance with the surface aggregation structure, the film exhibited lower hysteresis for water and higher hysteresis for nonpolar oils after thermal annealing compared with the case before thermal annealing. The film made of $\mathrm{P}\left(\mathrm{FAC}_{8}\right.$-co-DOPAm $)$ showed good thermal stability and healing property after the hydrophobicity was damaged by VUV irradiation. Moreover, the application of this polymer in the creation of superamphiphobic fabrics and organic/ inorganic hybrid coatings was proposed. The current study will be helpful for understanding the structure-property relation of fluoropolymers bearing catechol functions, as well as for better use of $R_{f}$ polymers in specific areas that still allow the use of materials containing long $\mathrm{R}_{\mathrm{f}}$ chains.

\section{EXPERIMENTAL SECTION}

4.1. Materials. The material 2-(perfluorooctyl)ethyl acrylate $\left(\mathrm{FAC}_{8}\right)$ was provided by Daikin Industries Co., Ltd. and was distilled under vacuum before polymerization. The material 2,2'-azobis(isobutyronitrile) (AIBN, Wako) was recrystallized from methanol. Dopamine hydrochloride (Sigma-Aldrich) and acryloyl chloride (Wako) were used as received. Triethylamine (Wako) and methanol $(\mathrm{MeOH}$, Wako) were distilled before use. Hexafluoroisopropanol (HFIP) and dichloropentafluoropropanes (HCFC-225s, a mixture of $225 \mathrm{ca}, \mathrm{CF}_{3} \mathrm{CF}_{2} \mathrm{CHCl}_{2}$, and $225 \mathrm{cb}$, $\mathrm{CCl}_{2} \mathrm{FCF}_{2} \mathrm{CHClF}$ ) were obtained from Wako Pure Chemical Industries and Asahi Glass Co., respectively. Halloysite nanotubes (HNTs) with external diameter of $30-70 \mathrm{~nm}$ and length of $1-3 \mu \mathrm{m}$ were purchased from Sigma-Aldrich.
4.2. Synthesis of $N$-(3,4-Dihydroxyphenethyl)acrylamide (DOPAm). DOPAm was synthesized according to a method described elsewhere. ${ }^{68}$ Dopamine hydrochloride $(10.0 \mathrm{~g}, 52.8 \mathrm{mmol})$ and triethylamine $(7.3 \mathrm{~mL}, 52.7 \mathrm{mmol})$ were dissolved in $\mathrm{MeOH}(100 \mathrm{~mL})$ and cooled in an ice bath. Tetrahydrofuran (THF) $(7 \mathrm{~mL})$ solution of acryloyl chloride $(7.0 \mathrm{~mL}, 71.5 \mathrm{mmol})$ and $\mathrm{MeOH}(10 \mathrm{~mL})$ solution of triethylamine $(9.5 \mathrm{~mL}, 68.1 \mathrm{mmol})$ were alternately dropped into the dopamine solution. The reaction mixture was stirred at room temperature for $2 \mathrm{~h}$, after which the solvent was removed by rotary evaporation. The residue was dissolved in ethyl acetate and washed with $1 \mathrm{M}$ hydrochloric acid and brine. The organic layer was dried over sodium sulfate, followed by filtration and concentration by evaporation. The precipitate was dissolved in ethyl acetate and recrystallized repeatedly to afford a white solid (yield $=60 \%$ ).

4.3. Copolymerization. $\mathrm{P}\left(\mathrm{FAC}_{8}\right.$-co-DOPAm $)$ was synthesized through a radical copolymerization. $\mathrm{FAC}_{8}(7.5 \mathrm{~g}, 14.5$ $\mathrm{mmol})$ and DOPAm (0.25 g, $1.2 \mathrm{mmol})$ were dissolved into 20 $\mathrm{mL}$ of HFIP. After adding AIBN (27.6 $\mathrm{mg}, 0.17 \mathrm{mmol})$, the solution was deoxygenated by argon bubbling for $30 \mathrm{~min}$; thereafter, it was placed in an oil bath thermostated at $58{ }^{\circ} \mathrm{C}$ and stirred for $10 \mathrm{~h}$ under the protection of argon. The reaction mixture was diluted with HFIP and dropped into $\mathrm{MeOH}$. The white product was collected by filtration and rinsed with $\mathrm{MeOH}$, after which it was dried in vacuum. In the literature, the catechol-bearing monomers are usually protected by alkylsilyl groups to avoid catechol oxidation during the polymerization. ${ }^{68,69}$ The polymerization of unprotected catechol-bearing monomers is also feasible, while sufficient deoxygenation (maintaining argon flow during the whole polymerization process) is crucial for a successful copolymerization. In case the deoxygenation was insufficient (argon flow was stopped, so oxygen could diffuse into the flask), the reaction mixture became colored after several hours and the viscosity did not increase regardless of the heating time. Scheme 3 shows the synthesis routes of DOPAm and $\mathrm{P}\left(\mathrm{FAC}_{8^{-}}\right.$ co-DOPAm) copolymers. The $\mathrm{PFAC}_{8}$ homopolymer was synthesized through a similar process.

The existence of catechol units in polymers has been verified by ${ }^{1} \mathrm{H}$ NMR in previous works. ${ }^{68,69}$ However, $\mathrm{P}\left(\mathrm{FAC}_{8}\right.$-coDOPAm) is difficult to be characterized by NMR spectroscopy due to its poor solubility in common NMR solvents. Herein, the existence of catechol groups in $\mathrm{P}\left(\mathrm{FAC}_{8}\right.$-co-DOPAm $)$ was confirmed by UV-vis spectroscopic analysis (Figure $\mathrm{S} 1 \mathrm{~b}$ ) because such a group has a typical absorption band at around $278 \mathrm{~nm} .^{70}$ The band absorbance was used to quantify the catechol amount in the copolymer by calibration with the

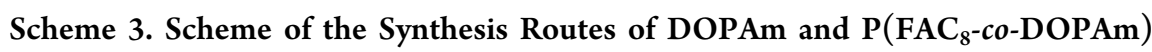
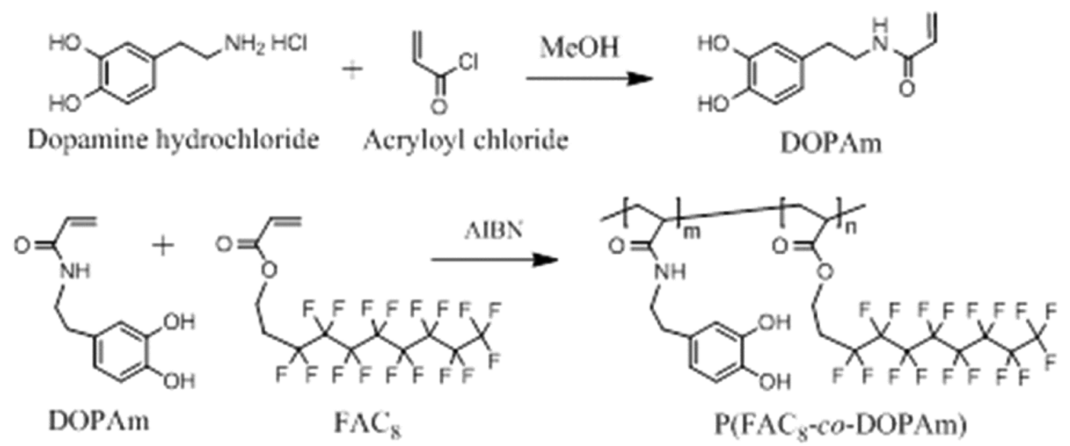
absorbance of DOPAm solutions, and the fraction of such a group was evaluated to be $0.15 \mu \mathrm{mol} \mathrm{mg}{ }^{-1}$. The $\mathrm{FAC}_{8} /$ DOPAm molar ratio in the copolymer can be calculated according to eq 1 , in which 207 and 518 are the molar masses of DOPAm and $\mathrm{FAC}_{8}$, respectively, and the $\mathrm{FAC}_{8} / \mathrm{DOPAm}$ molar ratio was calculated to be $n / m=12.5: 1$.

$$
\frac{m}{207 m+518 n} \mathrm{~mol} \mathrm{~g}^{-1}=0.15 \mu \mathrm{mol} \mathrm{mg}^{-1}
$$

4.4. Preparation of Polymer Films. The polymer solutions were prepared by dissolving $\mathrm{PFAC}_{8}$ or $\mathrm{P}\left(\mathrm{FAC}_{8}-\mathrm{co}\right.$ DOPAm) in HCFC-225s ( $1 \mathrm{wt} \%)$. The polymer films were prepared by spin-coating $(2000 \mathrm{rpm}, 30 \mathrm{~s})$ on clean silicon wafers. The annealed films were prepared by further placing the films on a hotplate $\left[55^{\circ} \mathrm{C}\right.$ for $\mathrm{P}\left(\mathrm{FAC}_{8}\right.$-co-DOPAm $)$ and 63 ${ }^{\circ} \mathrm{C}$ for $\left.\mathrm{PFAC}_{8}\right]$ for $12 \mathrm{~h}$.

4.5. Preparation of Superamphiphobic Coatings. Superamphiphobic coatings were prepared by two methods: (1) by coating the polymer on fabrics and (2) by fabricating organic/inorganic hybrid coating using HNT as the nanobuilding block. For coating fabrics, the coating solution was prepared by dissolving $\mathrm{P}\left(\mathrm{FAC}_{8}\right.$-co-DOPAm $)$ in $\mathrm{HCFC}-225 \mathrm{~s}$ to form a solution with a concentration of $1 \mathrm{wt} \%$. The fabric was immersed in the solution for $2 \mathrm{~min}$. After coating, the fabric was dried by $\mathrm{N}_{2}$ blowing. The organic/inorganic hybrid coatings were prepared by dropping and evaporation of a mixed solution of $\mathrm{P}\left(\mathrm{FAC}_{8}-\mathrm{co}-\mathrm{DOPAm}\right)$ and $\mathrm{HNT}\left[\mathrm{P}\left(\mathrm{FAC}_{8^{-}}\right.\right.$ co-DOPAm)/HNT weight ratio was $1: 2$, and the total concentration of $\mathrm{P}\left(\mathrm{FAC}_{8}-\mathrm{co}-\mathrm{DOPAm}\right)$ and $\mathrm{HNT}$ in the solution was $3.0 \mathrm{wt} \%$ ] onto the substrates. For removing the excess polymer, the mixed solution of $\mathrm{P}\left(\mathrm{FAC}_{8}-\mathrm{co}\right.$ DOPAm) and HNT was centrifuged at $8000 \mathrm{rpm}$ for $5 \mathrm{~min}$. The obtained $\mathrm{P}\left(\mathrm{FAC}_{8}\right.$-co-DOPAm $)$-adsorbed $\mathrm{HNT}$ was further washed three times by clean HCFC-225s using the same centrifugation procedure, after which it was dispersed into HCFC-225s with a concentration of $3.0 \mathrm{wt} \%$. The $\mathrm{P}\left(\mathrm{FAC}_{8}\right.$-co-DOPAm $)$-adsorbed $\mathrm{HNT}$ solution was also applied to prepare the organic/inorganic hybrid coatings by the dropping and evaporation method.

4.6. Characterization. UV-vis spectroscopy was conducted using a Shimadzu UV-vis-near-infrared (NIR) spectrophotometer UV 3600. Fourier transform infrared (FTIR) spectroscopic measurements were carried out with a Spectrum One (PerkinElmer Japan Co., Ltd.) with a resolution of $1.0 \mathrm{~cm}^{-1}$. FTIR spectra were acquired by averaging 64 scans in the wavenumber range of $4000-450 \mathrm{~cm}^{-1}$. X-ray photoelectron spectroscopic (XPS) measurements were carried out on an XPS-APEX (Physical Electronics Co. Ltd.) using a monochromatic $\mathrm{Al} \mathrm{K} \alpha$ X-ray source of $150 \mathrm{~W}$. The XPS data of the $\mathrm{P}\left(\mathrm{FAC}_{8}\right.$-co-DOPAm $)$ films were collected at a takeoff angle of $10^{\circ}$, while those of $\mathrm{HNT}$ and $\mathrm{P}\left(\mathrm{FAC}_{8}-\mathrm{co}\right.$-DOPAm $)$ adsorbed HNT were collected at a takeoff angle of $45^{\circ}$. The static contact angles were measured on an Attension Theta system (KSV Instruments Ltd.), equipped with a chargecoupled device (CCD) camera. Sliding angles were taken on a drop-shape analytical system, DSA 10 Mk2 (KRÜSS Optronic $\mathrm{GmbH}$, Germany), equipped with a tilting stage and a video camera. The advancing and receding angles were determined by increasing and decreasing the volume of liquids on the substrates, respectively. Differential scanning calorimetry (DSC) was performed on an SII-EXSTAR 6000 DSC 6200 instrument (Hitachi High-Tech Science Corporation, Tokyo, Japan) from -100 to $200{ }^{\circ} \mathrm{C}$ at a heating/cooling rate of $10^{\circ} \mathrm{C}$ $\min ^{-1}$. Thermogravimetric analysis (TGA) was performed on a thermo-balance SII-EXSTAR 6000 TGA 6200 instrument (Hitachi High-Tech Science Corporation, Tokyo, Japan) at a heating rate of $10{ }^{\circ} \mathrm{C} \mathrm{min}^{-1}$ under a nitrogen atmosphere from 25 to $500{ }^{\circ} \mathrm{C}$. Wide-angle X-ray diffraction (WAXD) was carried out at the BL05XU beamline in SPring- 8 . The wavelength of the X-ray was $\lambda=0.1 \mathrm{~nm}$. A $981 \times 1043$ pixel X-ray detector (PILATUS 1M, DECTRIS, Switzerland) was used to record the scattering patterns. The pixel resolution of the detector was $172 \mu \mathrm{m}$. The camera length was set as 117.44 $\mathrm{mm}$. The scattering vector was calibrated using the peak positions of cerium dioxide. The scattering vector, $q\left(\mathrm{~nm}^{-1}\right)$, is defined as $q=(4 \pi / \lambda) \sin \theta$, where $2 \theta$ is the scattering angle. Grazing incidence wide-angle X-ray diffraction (GI-WAXD) measurements were carried out at the BL40B2 beamline of SPring-8 using incident X-ray with a wavelength of $\lambda=0.10$ $\mathrm{nm}$. GI-WAXD data were obtained from the surface region at an incident angle of $\alpha_{\mathrm{i}}=0.08^{\circ}$. Diffractions from the sample films were detected in the in-plane and out-of-plane directions. Scanning electron microscopic (SEM) images were obtained using a JSM-7401F (JEOL, Inc.) instrument with an accelerating voltage of $3 \mathrm{kV}$.

\section{ASSOCIATED CONTENT}

\section{Supporting Information}

The Supporting Information is available free of charge at https://pubs.acs.org/doi/10.1021/acsomega.0c00439.

UV-vis and FTIR spectra for $\mathrm{PFAC}_{8}$ and $\mathrm{P}\left(\mathrm{FAC}_{8}-\mathrm{co}\right.$ DOPAm $)$; high-resolution XPS profiles of $\mathrm{P}\left(\mathrm{FAC}_{8}-\mathrm{co}\right.$ DOPAm) films before and after thermal annealing (PDF)

\section{AUTHOR INFORMATION}

\section{Corresponding Author}

Atsushi Takahara - International Institute for Carbon-Neutral Energy Research (WPI-I2CNER) and Institute for Materials Chemistry and Engineering, Kyushu University, Fukuoka 8190395, Japan; 이이이.org/0000-0002-0584-1525; Email: takahara@cstf.kyushu-u.ac.jp

\section{Authors}

Wei Ma - International Institute for Carbon-Neutral Energy Research (WPI-I2CNER), Kyushu University, Fukuoka 8190395, Japan

Bruno Ameduri - Institut Charles Gerhardt, University of Montpellier, CNRS, ENSCM, Montpellier, France; (1) orcid.org/0000-0003-4217-6664

Complete contact information is available at:

https://pubs.acs.org/10.1021/acsomega.0c00439

\section{Notes}

The authors declare no competing financial interest.

\section{ACKNOWLEDGMENTS}

The authors acknowledge the financial support of JSPS Grantin-aid for Scientific Research (A) (grant nos. 26248053 and 17H01221). WAXD measurements were conducted on the BL05XU beamline in SPring-8 with the approval of the Impact project. GI-WAXD measurements were conducted on the BL40B2 beamline in SPring-8 with the approval of the Japan Synchrotron Radiation Research Institute (JASRI) (proposal no. 2018A1177). The authors thank Chao-Hung Cheng 
(Graduate School of Engineering, Kyushu University) and Prof. Yuji Higaki (Faculty of Science and Technology, Oita University) for their assistance in WAXD and GI-WAXD measurements.

\section{REFERENCES}

(1) Hikita, M.; Tanaka, K.; Nakamura, T.; Kajiyama, T.; Takahara, A. Super-Liquid-Repellent Surfaces Prepared by Colloidal Silica Nanoparticles Covered with Fluoroalkyl Groups. Langmuir 2005, 21, 7299-7302.

(2) Banerjee, S.; Wehbi, M.; Manseri, A.; Mehdi, A.; Alaaeddine, A.; Hachem, A.; Ameduri, B. Poly(vinylidene fluoride) Containing Phosphonic Acid as Anticorrosion Coating for Steel. ACS Appl. Mater. Interfaces 2017, 9, 6433-6443.

(3) Bayer, I. S. On the Durability and Wear Resistance of Transparent Superhydrophobic Coatings. Coatings 2017, 7, No. 12.

(4) Rabnawaz, M.; Liu, G. Graft-Copolymer-Based Approach to Clear, Durable, and Anti-Smudge Polyurethane Coatings. Angew. Chem., Int. Ed. 2015, 54, 6516-6520.

(5) Cheng, M.; Song, M.; Dong, H.; Shi, F. Surface Adhesive Forces: A Metric Describing the Drag-Reducing Effects of Superhydrophobic Coatings. Small 2015, 11, 1665-1671.

(6) Wang, L.; Gong, Q.; Zhan, S.; Jiang, L.; Zheng, Y. Robust AntiIcing Performance of a Flexible Superhydrophobic Surface. Adv. Mater. 2016, 28, 7729-7735.

(7) Wang, L.; Chen, X.; Cao, X.; Xu, J.; Zuo, B.; Zhang, L.; Wang, X.; Yang, J.; Yao, Y. Fabrication of Polymer Brush Surfaces with Highly-Ordered Perfluoroalkyl Side Groups at The Brush End and Their Antibiofouling Properties. J. Mater. Chem. B 2015, 3, 43884400.

(8) Garrett, A. B. Teflon: Roy J. Plunkett. J. Chem. Educ. 1962, 39, 288.

(9) Puts, G. J.; Crouse, P.; Ameduri, B. M. Polytetrafluoroethylene: Synthesis and Characterization of the Original Extreme Polymer. Chem. Rev. 2019, 119, 1763-1805.

(10) Honda, K.; Morita, M.; Takahara, A. Room-Temperature Fabrication of Nanotexture in Crystalline Poly(fluoroalkyl acrylate) Thin Film. Soft Matter 2008, 4, 1400-1402.

(11) Liu, Y.; Higaki, Y.; Mukai, M.; Ohta, N.; Kabe, T.; Takahara, A. Smectic ordered structure and water repellency of a poly(fluoroalkyl acrylate) with a carbamate linker. Polym. J. 2019, 51, 189-198.

(12) Illy, N.; Urayeneza, D.; Maryasevskaya, A. V.; Michely, L.; Boileau, S.; Brissault, B.; Bersenev, E. A.; Anokhin, D. V.; Ivanov, D. A.; Penelle, J. Synthesis and Solid-State Properties of PolyC3 (Co)polymers Containing $(\mathrm{CH} 2-\mathrm{CH} 2-\mathrm{C}(\mathrm{COOR}) 2)$ Repeat Units with Densely Packed Fluorocarbon Lateral Chains. Macromolecules 2019, 52, 9199-9207.

(13) Yao, W.; Li, Y.; Huang, X. Fluorinated Poly(meth)acrylate: Synthesis and Properties. Polymer 2014, 55, 6197-6211.

(14) Honda, K.; Yamamoto, I.; Morita, M.; Yamaguchi, H.; Arita, H.; Ishige, R.; Higaki, Y.; Takahara, A. Effect of $\alpha$-Substituents on Molecular Motion and Wetting Behaviors of Poly(fluoroalkyl acrylate) Thin Films with Short Fluoroalkyl Side Chains. Polymer 2014, 55, 6303-6308.

(15) Honda, K.; Morita, M.; Sakata, O.; Sasaki, S.; Takahara, A. Effect of Surface Molecular Aggregation State and Surface Molecular Motion on Wetting Behavior of Water on Poly(fluoroalkyl methacrylate) Thin Films. Macromolecules 2010, 43, 454-460.

(16) Honda, K.; Morita, M.; Otsuka, H.; Takahara, A. Molecular Aggregation Structure and Surface Properties of Poly(fluoroalkyl acrylate) Thin Films. Macromolecules 2005, 38, 5699-5705.

(17) Lim, X. Tainted Water: The Scientists Tracing Thousands of Fluorinated Chemicals in Our Environment. Nature 2019, 566, 2629.

(18) Yamaguchi, H.; Kikuchi, M.; Kobayashi, M.; Ogawa, H.; Masunaga, H.; Sakata, O.; Takahara, A. Influence of Molecular Weight Dispersity of Poly\{2-(perfluorooctyl)ethyl acrylate $\}$ Brushes on Their Molecular Aggregation States and Wetting Behavior. Macromolecules 2012, 45, 1509-1516.

(19) Wang, Z. H.; Zuilhof, H. Self-Healing Fluoropolymer Brushes as Highly Polymer-Repellent Coatings. J. Mater. Chem. A 2016, 4, $2408-2412$

(20) Wang, Z. H.; Zuilhof, H. Self-Healing Superhydrophobic Fluoropolymer Brushes as Highly Protein-Repellent Coatings. Langmuir 2016, 32, 6310-6318.

(21) Zou, H. L.; Lin, S. D.; Tu, Y. Y.; Li, F.; Hu, J. W.; Liu, G. J.; Hu, S. Y.; Yang, G. H.; Yu, Z. W. An Aqueous Process for Durable Superamphiphobic Diblock Copolymer Coatings on Fabrics. Adv. Mater. Interfaces 2016, 3, No. 1500693.

(22) Zhang, G.; Hu, J.; Liu, G.; Zou, H.; Tu, Y.; Li, F.; Hu, S.; Luo, H. Bi-Functional Random Copolymers for One-Pot Fabrication of Superamphiphobic Particulate Coatings. J. Mater. Chem. A 2013, 1, 6226-6237.

(23) Grozea, C. M.; Rabnawaz, M.; Liu, G. J.; Zhang, G. W. Coating of Silica Particles by Fluorinated Diblock Copolymers and Use of The Resultant Silica for Superamphiphobic Surfaces. Polymer 2015, 64 $153-162$.

(24) Xiong, D.; Liu, G.; Duncan, E. J. S. Diblock-Copolymer-Coated Water- and Oil-Repellent Cotton Fabrics. Langmuir 2012, 28, 69116918.

(25) Xiong, D.; Liu, G.; Duncan, E. J. S. Simultaneous Coating of Silica Particles by Two Diblock Copolymers. ACS Appl. Mater. Interfaces 2012, 4, 2445-2454.

(26) Wang, X.; Ye, Q.; Liu, J.; Liu, X.; Zhou, F. Low Surface Energy Surfaces from Self-Assembly of Perfluoropolymer with Sticky Functional Groups. J. Colloid Interface Sci. 2010, 351, 261-266.

(27) Volkov, V. V.; Platé, N. A.; Takahara, A.; Kajiyama, T.; Amaya, N.; Murata, Y. Aggregation State and Mesophase Structure of CombShaped Polymers with Fluorocarbon Side Groups. Polymer 1992, 33, $1316-1320$

(28) Ahn, B. K.; Lee, D. W.; Israelachvili, J. N.; Waite, J. H. SurfaceInitiated Self-Healing of Polymers in Aqueous Media. Nat. Mater. 2014, 13, 867-872.

(29) Moon, R. J.; Martini, A.; Nairn, J.; Simonsen, J.; Youngblood, J. Cellulose nanomaterials review: structure, properties and nanocomposites. Chem. Soc. Rev. 2011, 40, 3941-3994.

(30) Li, H.; Zhang, W.; Xu, W.; Zhang, X. Hydrogen Bonding Governs the Elastic Properties of Poly(vinyl alcohol) in Water: SingleMolecule Force Spectroscopic Studies of PVA by AFM. Macromolecules 2000, 33, 465-469.

(31) Okuno, M.; Homma, O.; Kuo, A.-T.; Urata, S.; Koguchi, R.; Miyajima, T.; Ishibashi, T.-a. Molecular Orientations and Conformations of Air/Fluoroalkyl Acrylate Polymer Interfaces Studied by Heterodyne-Detected Vibrational Sum Frequency Generation. Macromolecules 2019, 8705.

(32) Cheng, D. F.; Masheder, B.; Urata, C.; Hozumi, A. Smooth Perfluorinated Surfaces with Different Chemical and Physical Natures: Their Unusual Dynamic Dewetting Behavior toward Polar and Nonpolar Liquids. Langmuir 2013, 29, 11322-11329.

(33) Owens, D. K.; Wendt, R. C. Estimation of the surface free energy of polymers. J. Appl. Polym. Sci. 1969, 13, 1741-1747.

(34) Wang, L.; McCarthy, T. J. Covalently Attached Liquids: Instant Omniphobic Surfaces with Unprecedented Repellency. Angew. Chem., Int. Ed. 2016, 55, 244-248.

(35) Flagg, D. H.; McCarthy, T. J. Rapid and Clean Covalent Attachment of Methylsiloxane Polymers and Oligomers to Silica Using $\mathrm{B}\left(\mathrm{C}_{6} \mathrm{~F}_{5}\right)_{3}$ Catalysis. Langmuir 2017, 33, 8129-8139.

(36) Cheng, D. F.; Urata, C.; Yagihashi, M.; Hozumi, A. A Statically Oleophilic but Dynamically Oleophobic Smooth Nonperfluorinated Surface. Angew. Chem., Int. Ed. 2012, 51, 2956-2959.

(37) Urata, C.; Masheder, B.; Cheng, D. F.; Hozumi, A. Unusual Dynamic Dewetting Behavior of Smooth Perfluorinated Hybrid Films: Potential Advantages over Conventional Textured and LiquidInfused Perfluorinated Surfaces. Langmuir 2013, 29, 12472-12482. 
(38) Park, J.; Urata, C.; Masheder, B.; Cheng, D. F.; Hozumi, A. Long Perfluoroalkyl Chains Are Not Required for Dynamically Oleophobic Surfaces. Green Chem. 2013, 15, 100-104.

(39) Masheder, B.; Urata, C.; Cheng, D. F.; Hozumi, A. Novel Transparent Zirconium-Based Hybrid Material With Multilayered Nanostructures: Studies of Surface Dewettability Toward Alkane Liquids. ACS Appl. Mater. Interfaces 2013, 5, 154-163.

(40) Xue, L.; Han, Y. Inhibition of Dewetting of Thin Polymer Films. Prog. Mater. Sci. 2012, 57, 947-979.

(41) Sheiko, S.; Lermann, E.; Möller, M. Self-Dewetting of Perfluoroalkyl Methacrylate Films on Glass. Langmuir 1996, 12, 4015-4024.

(42) Henn, G.; Bucknall, D. G.; Stamm, M.; Vanhoorne, P.; Jérôme, R. Chain End Effects and Dewetting in Thin Polymer Films. Macromolecules 1996, 29, 4305-4313.

(43) Miyamoto, K.; Hosaka, N.; Kobayashi, M.; Otsuka, H.; Yamada, N.; Torikai, N.; Takahara, A. Dewetting Inhibition and Interfacial Structures of Silsesquioxane-terminated Polystyrene Thin Films. Polym. J. 2007, 39, 1247-1252.

(44) Hosaka, N.; Torikai, N.; Otsuka, H.; Takahara, A. Structure and Dewetting Behavior of Polyhedral Oligomeric Silsesquioxane-Filled Polystyrene Thin Films. Langmuir 2007, 23, 902-907.

(45) Kubo, M.; Takahashi, Y.; Fujii, T.; Liu, Y.; Sugioka, K.-i.; Tsukada, T.; Minami, K.; Adschiri, T. Thermal Dewetting Behavior of Polystyrene Composite Thin Films with Organic-Modified Inorganic Nanoparticles. Langmuir 2014, 30, 8956-8964.

(46) Cao, P.; Bai, P.; Omrani, A. A.; Xiao, Y.; Meaker, K. L.; Tsai, H.-Z.; Yan, A.; Jung, H. S.; Khajeh, R.; Rodgers, G. F.; Kim, Y.; Aikawa, A. S.; Kolaczkowski, M. A.; Liu, Y.; Zettl, A.; Xu, K.; Crommie, M. F.; Xu, T. Preventing Thin Film Dewetting via Graphene Capping. Adv. Mater. 2017, 29, No. 1701536.

(47) Lee, H.; Dellatore, S. M.; Miller, W. M.; Messersmith, P. B. Mussel-Inspired Surface Chemistry for Multifunctional Coatings. Science 2007, 318, 426-430.

(48) Lee, H.; Lee, Y.; Statz, A. R.; Rho, J.; Park, T. G.; Messersmith, P. B. Substrate-Independent Layer-by-Layer Assembly by Using Mussel-Adhesive-Inspired Polymers. Adv. Mater. 2008, 20, 16191623.

(49) Li, L.; Yan, B.; Yang, J.; Chen, L.; Zeng, H. Novel MusselInspired Injectable Self-Healing Hydrogel with Anti-Biofouling Property. Adv. Mater. 2015, 27, 1294-1299.

(50) Ma, Y.; Ma, S.; Wu, Y.; Pei, X.; Gorb, S. N.; Wang, Z.; Liu, W.; Zhou, F. Remote Control over Underwater Dynamic Attachment/ Detachment and Locomotion. Adv. Mater. 2018, 30, No. 1801595.

(51) Ye, Q.; Wang, X.; Li, S.; Zhou, F. Surface-Initiated RingOpening Metathesis Polymerization of Pentadecafluorooctyl-5norbornene-2-carboxylate from Variable Substrates Modified with Sticky Biomimic Initiator. Macromolecules 2010, 43, 5554-5560.

(52) Zeng, H.; Hwang, D. S.; Israelachvili, J. N.; Waite, J. H. Strong Reversible $\mathrm{Fe}^{3+}$-Mediated Bridging Between Dopa-Containing Protein Films in Water. Proc. Natl. Acad. Sci. U.S.A. 2010, 107, 12850-12853.

(53) Zhang, J.; Zhang, L.; Cui, X.; Gong, L.; Xiang, L.; Shi, C.; Hu, W.; Zeng, H. Scalable Polyzwitterion-Polydopamine Coating for Regenerable Oil/Water Separation and Underwater Self-Cleaning of Stubborn Heavy Oil Fouling without Pre-Hydration. Chem. Commun. 2018, 54, 9734-9737.

(54) Padhan, A. K.; Mandal, D. Thermo-reversible self-healing in a fluorous crosslinked copolymer. Polym. Chem. 2018, 9, 3248-3261.

(55) Banerjee, S.; Tawade, B. V.; Améduri, B. Functional fluorinated polymer materials and preliminary self-healing behavior. Polym. Chem. 2019, 10, 1993-1997.

(56) Tuteja, A.; Choi, W.; Ma, M. L.; Mabry, J. M.; Mazzella, S. A.; Rutledge, G. C.; McKinley, G. H.; Cohen, R. E. Designing Superoleophobic Surfaces. Science 2007, 318, 1618-1622.

(57) Lee, S. Y.; Rahmawan, Y.; Yang, S. Transparent and Superamphiphobic Surfaces from Mushroom-Like Micropillar Arrays. ACS Appl. Mater. Interfaces 2015, 7, 24197-24203.

(58) Wu, W. C.; Wang, X. L.; Wang, D. A.; Chen, M.; Zhou, F.; Liu, W. M.; Xue, Q. J. Alumina Nanowire Forests via Unconventional
Anodization and Super-Repellency Plus Low Adhesion to Diverse Liquids. Chem. Commun. 2009, 1043-1045.

(59) Ge, D.; Yang, L.; Zhang, Y.; Rahmawan, Y.; Yang, S. Transparent and Superamphiphobic Surfaces from One-Step Spray Coating of Stringed Silica Nanoparticle/Sol Solutions. Part. Part. Syst. Charact. 2014, 31, 763-770.

(60) Wang, H.; Xue, Y.; Ding, J.; Feng, L.; Wang, X.; Lin, T. Durable, Self-Healing Superhydrophobic and Superoleophobic Surfaces from Fluorinated-Decyl Polyhedral Oligomeric Silsesquioxane and Hydrolyzed Fluorinated Alkyl Silane. Angew. Chem., Int. Ed. 2011, 50, 11433-11436.

(61) Zhou, H.; Wang, H.; Niu, H.; Gestos, A.; Lin, T. Robust, SelfHealing Superamphiphobic Fabrics Prepared by Two-Step Coating of Fluoro-Containing Polymer, Fluoroalkyl Silane, and Modified Silica Nanoparticles. Adv. Funct. Mater. 2013, 23, 1664-1670.

(62) Zhou, H.; Wang, H.; Niu, H.; Fang, J.; Zhao, Y.; Lin, T. Superstrong, Chemically Stable, Superamphiphobic Fabrics from Particle-Free Polymer Coatings. Adv. Mater. Interfaces 2015, 2, No. 1400559

(63) Xiong, D.; Liu, G. J.; Hong, L. Z.; Duncan, E. J. S. Superamphiphobic Diblock Copolymer Coatings. Chem. Mater. 2011, 23, 4357-4366.

(64) Ma, W.; Higaki, Y.; Takahara, A. Superamphiphobic Coatings from Combination of a Biomimetic Catechol-Bearing Fluoropolymer and Halloysite Nanotubes. Adv. Mater. Interfaces 2017, No. 1700907.

(65) Lvov, Y.; Abdullayev, E. Functional Polymer-Clay Nanotube Composites with Sustained Release of Chemical Agents. Prog. Polym. Sci. 2013, 38, 1690-1719.

(66) Steele, A.; Bayer, I.; Loth, E. Inherently Superoleophobic Nanocomposite Coatings by Spray Atomization. Nano Lett. 2009, 9, 501-505.

(67) Milionis, A.; Dang, K.; Prato, M.; Loth, E.; Bayer, I. S. Liquid Repellent Nanocomposites Obtained from One-Step Water-Based Spray. J. Mater. Chem. A 2015, 3, 12880-12889.

(68) Xu, H.; Nishida, J.; Ma, W.; Wu, H.; Kobayashi, M.; Otsuka, H.; Takahara, A. Competition between Oxidation and Coordination in Cross-Linking of Polystyrene Copolymer Containing Catechol Groups. ACS Macro Lett. 2012, 1, 457-460.

(69) Nishida, J.; Kobayashi, M.; Takahara, A. Gelation and Adhesion Behavior of Mussel Adhesive Protein Mimetic Polymer. J. Polym. Sci., Part A: Polym. Chem. 2013, 51, 1058-1065.

(70) Ryou, M.-H.; Kim, J.; Lee, I.; Kim, S.; Jeong, Y. K.; Hong, S.; Ryu, J. H.; Kim, T.-S.; Park, J.-K.; Lee, H.; Choi, J. W. MusselInspired Adhesive Binders for High-Performance Silicon Nanoparticle Anodes in Lithium-Ion Batteries. Adv. Mater. 2013, 25, 1571-1576. 